\title{
Was the Manchester Baby conceived at Bletchley Park?
}

\author{
David Anderson ${ }^{1}$ \\ School of Computing, University of Portsmouth, Portsmouth, PO1 3HE, UK \\ This paper is based on a talk given at the Turing 2004 conference held at the University of \\ Manchester on the $5^{\text {th }}$ June 2004. It is published by the British Computer Society on \\ http://www.bcs.org/ewics. It was submitted in December 2005; final corrections were made \\ and references added for publication in November 2007.
}

\section{Preamble}

In what follows, I look, in a very general way, at a particularly interesting half century, in the history of computation. The central purpose will be to throw light on how computing activity at the University of Manchester developed in the immediate post-war years and, in the context of this conference, to situate Alan Turing in the Manchester landscape. One of the main methodological premises on which I will depend is that the history of technology is, at heart, the history of people. No historically-sophisticated understanding of the development of the computer is possible in the absence of an appreciation of the background, motivation and aspirations of the principal actors. The life and work of Alan Turing is the central focus of this conference but, in the Manchester context, it is also important that attention be paid to F.C. Williams, T. Kilburn and M.H.A. Newman.

\section{The Origins of Computing in Pre-war Cambridge}

David Hilbert's talk at the Sorbonne on the morning of the 8th August 1900 in which he proposed twenty-three "future problems", effectively set the agenda for mathematics research in the 20th century. The tenth of Hilbert's questions ${ }^{2}$ led directly to Hilbert and Ackerman's 1928 formulation of the Entscheidungsproblem (Hilbert \& Ackerman, 1928 p.134), which Hilbert considered to be "the central problem of mathematical logic" (Davis, 1982 p.134). The essence of the question was: could there exist, at least in principle, a definite method or process involving a finite number of steps, by which the validity of any given first-order logic statement might be decided?

The original 1900 formulation of the problem was not finally answered until 1970 (Matiyasevich, 1970) but the 1928 version proved more immediately tractable. Turing seems first to have encountered the Entscheidungsproblem around the Spring of 1935 when he was a student on Max Newman's Part III course on the foundations of mathematics. Solving the Entscheidungsproblem rigorously was entirely dependent on the extent to which a formalisation of the notion of "process" could be devised and it was this task which Turing accomplished so dramatically. As Max Newman recalled in 1975:

"Oh I knew [Turing] very well. ...I believe it all started because he attended a lecture of mine on foundations of mathematics and bgic in which I had mentioned in the lecture the importance of having such a definition and I think I said, in the course of this lecture, that what is meant by saying that the process is constructive is that it's purely a mechanical...

\footnotetext{
${ }^{1}$ Email david.anderson@ port.ac.uk. http://www.cdpa.co.uk/UoP/

${ }^{2}$ The determination of the solvability of a diophantine equation.
} 
machine and I may even have said a machine can do it. But he took the notion and really tried to follow it right up and did produce this extraordinary definition of a perfectly general, what he called, computable function. Thus, giving the first idea really of a perfectly general computing machine."(Evans, 1975) 3

In the middle of April 1936, Turing gave Newman the draft ${ }^{4}$ of his answer in the negative to Hilbert's question. (Hodges, 1992 p.109) Turing's solution was an extraordinary combination of the physical and the abstract at the heart of which was an idealised description of a person carrying out numerical computation.

"We may compare a man in the process of computing a real number to a machine which is only capable of a finite number of conditions q1, q2,..., $q R$ which will be called " $m$-configurations". The machine is supplied with a "tape", (the analogue of paper) running through it, and divided into sections (called "squares") each capable of bearing a "symbol". At any moment there is just one square, say the $\mathrm{r}-\mathrm{th}$, bearing the symbol $S(\mathrm{r})$ which is "in the machine". We may call this square the "scanned square". The symbol on the scanned square may be called the "scanned symbol". The "scanned symbol" is the only one of which the machine is, so to speak, "directly aware". However, by altering its $\mathrm{m}$-configuration the machine can effectively remember some of the symbols which it has "seen" (scanned) previously. The possible behaviour of the machine at any moment is determined by the m-configuration $q$ and the scanned symbol $S(\mathrm{r})$. This pair qn, $S(\mathrm{r})$ will be called the "configuration": thus the configuration determines the possible behaviour of the machine. In some of the configurations in which the scanned square is blank (i.e. bears no symbol) the machine writes down a new symbol on the scanned square: in other configurations it erases the scanned symbol. The machine may also change the square which is being scanned, but only by shifting it one place to right or left. In addition to any of these operations the m-configuration may be changed. Some of the symbols written down will form the sequence of figures which is the decimal of the real number which is being computed. The others are just rough notes to "assist the memory". It will only be these rough notes which will be liable to erasure” (A. M. Turing, 1936 pp.231-2)

Following Church (Church, 1937) we have come to call this characterisation a "Turing machine" and it is today so familiar a notion that it is easy to overlook the extent to which it must have seemed at the time "shockingly industrial" (Hodges, 1992 p.107).

Newman read the paper in mid May and was sceptical in the first instance, believing it must be possible to construct a machine capable of doing more than Turing's machine could do. Soon after Newman had convinced himself of the correctness of Turing's reasoning, he received a copy of Alonzo Church's “An Unsolvable Problem of Elementary Number Theory" (Church, 1936), which while anticipating Turing's

\footnotetext{
${ }^{3}$ I am indebted to JAN Lee for first directing my attention to the Evans' "Pioneers of Computing" interviews. I first actually heard the M.H.A. Newman interview in 1998 courtesy of B.J. Copeland who was kind enough to let me hear his copy when I was acting as a visiting researcher at the University of Canterbury, New Zealand.

${ }^{4}$ This was finally published as A.M. Turing (1936)
} 
result did so by a very different, more circuitous and, in some ways weaker, method. Turing's paper was submitted to the Proceedings of the London Mathematical Society on $28^{\text {th }}$ May 1936 and was refereed by Church. It is widely considered as perhaps the most important "computing" paper ever published.

Turing's election, fifteen years later, as a Fellow of the Royal Society was on the basis of his work on the Entscheidungsproblem. However, he did enjoy some more immediate success. In 1935, aged just 22, Turing secured a King's College Fellowship having submitted a dissertation entitled 'On the Gaussian Error Function' in which he proved or, more accurately, re-proved, the Central Limit Theorem ${ }^{5}$. In 1936, the same work earned Turing the prestigious Smith's Prize for Mathematics ${ }^{6}$.

Typically, Turing's work on the Entscheidungsproblem was a solo effort, par excellence, as Newman wrote to Church on the $31^{\text {st }}$ May 1936:

"I should mention that Turing's work is entirely independent: he has been working without any supervision or criticism from anyone. This makes it all the more important that he should come into contact as soon as possible with the leading workers in this line, so that he should not develop into a confirmed solitary." (Hodges, 1992 pp.112-3)

Unfortunately, Newman's hopes for Turing, in this respect at least, were dashed. With the departure from Princeton the year before of Gödel, Kleene, Rosser and Bernays, logicians were fairly thin on the ground and Church was, like Turing, a somewhat retiring figure not much given to conversation.

\section{The Institute of Advanced Study, Princeton, USA}

Newman made arrangements for Turing to attend Princeton with the purpose of working towards a doctoral degree under Church's supervision. This, Turing's "deepest and most difficult work" (Hodges, 2004), was completed in 1938. It "investigated the structure of uncomputable functions, with a suggestion that these were related to human intuition." (Hodges, 2004).

According to Copeland and Proudfoot (Copeland, 1998) (Copeland \& Proudfoot, 1999), Turing's $1938 \mathrm{Ph}$.D. thesis was also noteworthy for having anticipated in detail the idea of "hypercomputation"7. However, Hodges (1999) (2007) and Davis (2004) (2006) have between them raised a number of serious and so-far unsatisfactorily-answered questions concerning the

\footnotetext{
${ }^{5}$ Turing's work was carried out in 1934. Characteristically, he had not troubled to find out if the result he was after had already been achieved. Unfortunately it had: (See Lindeberg, 1922). (Hodges, 1992 p.88) reports that Turing was advised, "provided that due explanation was given, it might still be acceptable as original work for a King's fellowship dissertation”.

${ }^{6}$ Two annual prizes for awarded for proficiency in mathematics and natural philosophy. The Smith's Prize was established in 1768 by a bequest from the Master of Trinity College, Robert Smith. The prizes have been awarded every year since, except for 1917 when there were no candidate. Other winners include: G. B. Airy 1823, G. G. Stokes 1841, Arthur Cayley 1842, William Thomson (Lord Kelvin) 1845, J. Clerk Maxwell 1854, J. W. L. Strutt (Lord Rayleigh) 1865, J. J. Thomson 1880, E. T. Whittaker 1896, G. H. Hardy 1901,

Arthur Eddington 1907, J. E. Littlewood 1908 and Fred Hoyle 1938. For a good account of the history of the prize (See Barrow-Green, 1999).

7 This term is not Turing's but was introduced by Copeland to describe various speculative methods for computing non-Turing-computable functions.
} 
singular interpretation of Turing's views promoted by Copeland and Proudfoot as well as providing strong grounds for doubting the prospects for "hypercomputation".

Randell (1972) has suggested that von Neumann's thinking was influenced by Turing's pre-war work on the Entscheidungsproblem and cites the recollections of Stanley Frankel as evidence that von Neumann was quite open in acknowledging his debt to, and the central importance of, Turing's work:

"I know that in or about 1943 or '44 von Neumann was well aware of the fundamental importance of Turing's paper of 1936 'On computable numbers ...' which describes in principle the 'Universal Computer' of which every modern computer (perhaps not ENIAC as first completed but certainly all later ones) is a realization. Von Neumann introduced me to that paper and at his urging I studied it with care. Many people have acclaimed von Neumann as the 'father of the computer' (in a modern sense of the term) but I am sure that he would never have made that mistake himself. He might well be called the midwife, perhaps, but he firmly emphasized to me, and to others I am sure, that the fundamental conception is owing to Turing insofar as not anticipated by Babbage, Lovelace, and others. In my view von Neumann's essential role was in making the world aware of these fundamental concepts introduced by Turing and of the development work carried out in the Moore school and elsewhere. Certainly I am indebted to him for my introduction to these ideas and actions. Both Turing and von Neumann, of course, also made substantial contributions to the 'reduction to practice' of these concepts but I would not regard these as comparable in importance with the introduction and explication of the concept of a computer able to store in its memory its program of activities and of modifying that program in the course of these activities." (Frankel, 1972)

While it does appear that Turing's work was, by 1943-44, influential on von Neumann, the precise extent of the influence and the exact date when and the means by which it was first exercised is rather less clear. Writing on June $1^{\text {st }} 1937$ von Neumann remarks:

"Mr. A.M. Turing has informed me that he is applying for a Proctor Visiting Fellowship to Princeton University for the academic year 1937-1938. I should like to support his application and to inform you that I know Mr. Turing very well from previous years: during the last term of 1935, when I was a visiting professor in Cambridge, and during 1936-1937, which year Mr. Turing has spent in Princeton, I had opportunity to observe his scientific work. He has done good work in branches of mathematics in which I am interested, namely: theory of almost periodic functions, and theory of continuous groups" (Hodges, 1992 p.131)

Von Neumann makes no reference here to Turing's most substantial and mathematically significant work, "On Computable Numbers". This would be perfectly understandable if von Neumann was unaware of the paper until some time after the middle of 1937. Consequently, it seems unlikely he would have, before that time, been discussing with Turing the latter's assault

\footnotetext{
${ }^{8}$ A copy of the original Von Neumann letter is held in Turing's file at the Department of Mathematics, Princeton University.
} 
on the Entscheidungsproblem (or how, by extension, it might be possible to actually build a universal Turing machine). Hodges suggests that Turing may have been "too shy to press his work upon the 'mathematical bigwig'(Hodges, 1992 p.132). Such reticence is entirely consistent with what we know of Turing's character. A year later, in the Summer of 1938, von Neumann does appear to have encountered "On Computable Numbers" and was proposing to Stanislaw Ulam, a game of "writing down on a piece of paper as big a number as we could, defining it by a method which indeed has something to do with some schemata of Turing' s" (Hodges, 1992 p. 145$)^{9}$.

It may reasonably be concluded that any relevant personal communication which took place between Turing and von Neumann during 1936-38 was fairly limited in character. This view is supported by comments made by von Neumann's long-term associate Herman Goldstine, in conversation with Chris Evans in 1975:

"EVANS - Could you say whatever you can about what you know about von Neumann's early interest and the way in which he directed the... the thinking so that the projects were sort of inevitably drawn towards the idea of an electronic computer?

GOLDSTINE - Von Neumann was very well acquainted with Turing and Turing's work. I know he had very substantial admiration for... for Turing and I think that acquaintance had a lot to do with the ultimate direction in which the computer went.

EVANS - I wonder how much cross fertilisation there was. Sometimes some people will say not that they barely met but that the exchange of information between them was slight and other people, if I take the line that you are advancing, suggest that there was a fair bit of communication between them.

GOLDSTINE - No, I don't know that there was communication, I don't think that's true. I think the fact is that von Neumann understood all about Turing's thesis and when the time came he brought that out of the recesses of his memory and utilised them, those ideas, for his own purposes." (Evans, 1976g)

The contemporary record equally gives no reason to believe that von Neumann was in any way instrumental in shaping Turing's thinking during this period. Indeed, ever the confirmed solitary, being influenced by others was somewhat alien to Turing's character. As Mike Woodger ${ }^{10}$ put it:

"Well you have to understand that Turing was an utter individualist, that not a single thought would he allow in his head that wasn't selfgenerated. This is rather an exaggeration but it did seem that way. He worked at the Institute of Advanced Study in Princeton USA before the war and knew von Neumann at that time. I'm sure he had a healthy

\footnotetext{
${ }^{9}$ Hodges is quoting from (Ulam, 1999).

${ }^{10}$ Woodger worked with Turing at the National Physical Laboratory from 1946 and made a contribution to the design of the ACE (Automatic Computing Engine) test assembly.
} 
respect for these people but he would always do things for himself both

theoretically and practically if at all possible." (Lavington, 1976)

In the Spring of 1938, von Neumann made Turing the offer of a research assistantship at the Institute of Advanced Study. Turing turned down the opportunity and, in mid-July of the same year, returned to England where, almost immediately, he attended a course held in the headquarters of the Government Code and Cipher School (GC\&CS) (Hodges, 1992 p.148). By the start of 1939, Turing was attending similar training sessions every two or three weeks and was attached to Dilly Knox ${ }^{11}$ and Peter Twinn. ${ }^{12}$ Turing continued his relationship with the University, he still held a Fellowship at King's College, and for a short period, beginning in the Spring of 1939, Turing delivered a course in the foundations of mathematics in the Faculty of Mathematics ("Cambridge University Reporter," 1939 p.100) . On the $4^{\text {th }}$ September 1939 , immediately following the British declaration of war on Germany, Turing reported to Bletchley Park which, since August of the same year, had been the new home of the GC\&CS ${ }^{13}$.

\section{Bletchley Park and the Birth of the Digital Computer}

No effort will be made here to describe in detail Turing's cryptanalytic work. Suffice it to say that his contributions were centrally important to the overall effort.

The first notable inroads against Enigma were made far from Bletchley Park by the Polish Army "Cipher Bureau" (Biuro Szyfrów) headed by Captain Maksymilian Ciezki. A small team of cryptanalysts, Marian Rejewski, Jerzy Rózycki and Henryk Zygalski enjoyed considerable success in deducing the rotor wiring of the Enigma cipher machines, using a combination of acute observation, mathematical inspiration and the application of elementary group theory. In the Autumn of 1938, Rejewski developed an electro-mechanical device called the "Bomba" to automate and accelerate the process of searching for "keys" in the cipher text of intercepted messages. In December of the same year, the Germans produced an improvement in the Enigma $^{14}$ with the consequence that the Biuro Szyfrów did not any longer have the resources to prosecute successfully their cryptanalytic effort. A meeting was arranged between the Biuro Szyfrów and their French and British counterparts at which the Poles brought their opposite numbers up to speed.

Interestingly, the idea of deploying a mechanised attack on the mechanically generated Enigma cipher never seems to have occurred to anyone at the GC\&CS prior to their meeting with the

\footnotetext{
${ }^{11}$ Alfred Dillwyn 'Dilly' Knox was a Greek scholar from King's College Cambridge. He is credited as being the first person at the GC\&CS to achieve success against Enigma.

12 Peter Frank George Twinn was a mathematician from Brasenose College, Oxford. He was recruited to GC \&CS early in 1939 after answering an advertis ement. Twinn became the first British cryptographer to decipher a message encoded by a German Enigma coding machine while he was working at the Government Code and Cipher School (GC\&CS) at Bletchley Park during the Second World War. For further details see the Times obituaries column, November 24, 2004.

${ }^{13}$ The previous location having been Broadway Buildings, 54 Broadway, London.

${ }^{14}$ They increased the number of possible rotors from three to five meaning that instead of there being just six ways to arrange the rotors in a three rotor Enigma machine there were now sixty.
} 
Poles in July 1939 (Hodges, 1992 p.175) and it was late 1939 before R.V. Jones ${ }^{15}$ suggested to Edward Travis ${ }^{16}$ marking or punching

"a paper or film in any one of 26 positions, corresponding to the letter coming out of the machine.... and to run the resulting record past a battery of photocells, so that each could count the number of times of occurrence of the letter that it was looking for. After a given total count had been achieved, the frequency distribution between the letters could be compared with the one appropriate to the language, which could have been set up on some kind of template."(Jones, 1978)

This very promising idea led to a positive meeting with Turing but although strikingly similar to the approach later used by Colossus, the mechanised attack on Enigma embodied by the British version of the Bomba, the BTM Bombe, was founded on the search for logical consistency based on hypothesising a "crib" or probable word in the originating plain text.

The first Bombe, based on Turing's original design ${ }^{17}$, arrived at Bletchley Park in March 1940 and was encouragingly named "Victory". The machine was successful to such an extent that by the late Spring of 1945, there were some two hundred and eleven Bombes in service, requiring a staff approaching two thousand to meet their operational needs. ${ }^{18}$

The Bombe was designed for a single purpose and was not, it should be stressed, a universal Turing machine. But if "On computable numbers" marked the first theoretical step in a process then the success of the Bombe, by encouraging further development of cryptanalytic machinery, represented an important engineering first step. The dance which had started with a throwaway remark of Newman's in the Spring of 1935 was now gathering pace and the remaining steps, which would take another eight years to culminate in the first successful run of the Manchester Small Scale Experimental Machine (SSEM) or "Baby", would each involve Turing, Newman or both. This observation is not intended to detract from the vital roles played, in various developments, by other leading figures which were, naturally, of great importance.

Turing's contribution to the theory of computing is now so widely-regarded as singular that it is worth sounding a cautionary note about assuming that his contemporaries read, understood or were directly influenced by his published work. The documentary record suggests that Turing's writing only really came to be seen as important some years after his death in 1954 and long after the first real computers were built. Such effect as he had on the early development of the storedprogram computer appears to have been accomplished either directly by means of personal contact or indirectly through friends and colleagues. In consequence, it is likely that we will never be in a position to say with any degree of precision exactly what impact Turing had on the early development of computers.

Whatever tendency there may be to exaggerate Turing's role there is a tendency of at least equal strength to under-estimate the part played by his lifelong friend Max Newman Newman's often

\footnotetext{
${ }^{15}$ Reginald Victor Jones went on to solve a number of tough Scientific and Technical Intelligence problems during World War II and is generally known today as the "father of S\&T Intelligence" (See Clark, 2007).

${ }^{16}$ Edward Wilfred Harry Travis became the director of Bletchley Park during World War II. At the time of this exchange he was deputy to Alexander Guthrie (Alastair) Denniston.

${ }^{17}$ Without Gordon Welchman's diagonal board improvement which was not implemented for another five months.

${ }^{18}$ In addition to the machines installed at Bletchley Park there were five Bombe "outstations" located at Adstock, Eastcote, Gayhurst, Stanmore, and Wavendon.
} 
understated manner and admirable aversion to claiming credit for his achievements left him vulnerable to being thought of as much less prominent in the history of post-war British computing than ought to be the case.

Newman was not an early recruit to Bletchley Park. The initiative appears to have come from Patrick Blackett who wrote to the Director of Naval Intelligence, Rear Admiral John Henry Godfrey, on the $13^{\text {th }}$ May 1942 recommending Newman as

"... one of the most intelligent people I know, being a first-class pure mathematician, an able philosopher, a good chess player and musician," (Blackett, 1942 p.2)

In the early Autumn of 1942 Newman took up his post as a Senior Assistant assigned to Major G.W. (Gerry) Morgan's research section and was assigned to the "Testery" which was a subsection under Major Ralph Tester, applying hand methods to decrypting so called "Fish"19 signals. This was not a task to which Newman felt well suited and he was actively considering a return to Cambridge when he saw the possibility of automating one of the techniques (Banks, 1996 p.8). The approach in question relied on complex statistical methods the effective application of which would require the building of machines. Newman took the idea to Travis, whose approval to set up a new section (known afterwards as the 'Newmanry') was secured quickly, and before the Winter of 1942, contacts were made in the Post Office with a view to securing the services of electrical engineers to undertake the project which eventually came under the leadership of the Telecommunications Research Establishment's (TRE) engineer Charles Eryl (C.E.) Wynn-Williams.

The first machines, known as Robinsons, were delivered to Newman's Hut F by April 1943. Although producing some valuable results, the Robinsons were not sufficiently reliable nor were they fast enough in operation for the demands of cryptanalytic work in the Bletchley Park context. The essential technical problem was that they made use of a pair of long paper tapes, the passage of which through Robinson needed to be synchronised. This was a task which proved beyond the skills of the engineers to accomplish. A different approach was required and a possible way forward was suggested by Post Office engineer, Tommy Flowers before the first Robinsons had even been assembled. The kernel of his idea was to store one of the paper tapes (containing the Fish key-patterns) electronically, thereby doing away with the need for synchronisation. In practice, this would require the simultaneous and reliable deployment of a colossal number of thermionic valves. Such a proposal ran counter to the general understanding at the time that valves were prone to breakdown at a rate which would render any attempt at such large-scale co-ordinated use of valves doomed to failure. ${ }^{20}$ Flowers was confident however and Newman, in what must have seemed a reckless move at the time, lent his support to the proposal, effectively overruling the concerns of the both the builder of the Bombe, Harold 'Doc' Keen and of the Robinson, Wynn-Williams. Even with Newman's backing the plan failed to secure official support from Bletchley Park. Undeterred, Flowers effectively bypassed Bletchley Park, obtaining approval instead from Gordon Radley, the Director of the Dollis Hill Research Station. Working closely with Sydney Broadhurst and William Chandler, Flowers then set about the process of design and construction of what is widely acknowledged today as the world's first working digital electronic computer. The rapidity and effectiveness with which Flowers' team successfully completed their task was quite remarkable. The process of

\footnotetext{
${ }^{19}$ German High Command ciphers produced by Lorenz machines. These devices employed an encryption scheme more complicated even than that used by Enigma.

${ }^{20}$ Exactly the same concerns were raised against Presper Eckert's plan for the ENIAC.
} 
construction was begun in February 1943 and in a little less than a year the Colossus was up and running at Bletchley Park.

Turing was aware of these developments and may have discussed some initial ideas with Flowers even before Newman, but it is difficult to gauge the extent to which he played an active part in the detailed development of Colossus. Turing did visit Flowers at Dollis Hill and had discussions there about Colossus but appears to have had very little input at meetings held at Bletchley Park. The National Archives hold a number of photographs of the Colossus accompanying which is a caption, by Benjamin, fairly summarising the roles of the principal players:

"The requirement for the machine was formulated by Professor M.H.A. Newman and the development was undertaken by a small team led by T.H. Flowers. A Turing was working in the same department at that time, and his earlier work had its full influence on the design concept."(The National Archives, 1943)

\section{Newman's Character and Managerial Style}

It is perhaps appropriate here to discuss briefly the character and managerial style of Newman as this discussion will play a part in understanding better the nature and extent of his involvement in the British computing scene in the immediate post-war period.

At first contact Newman was perhaps a little austere but his manner was generally affable and occasionally playful. Speaking in 1975 , Jack Good recalled that:

"Typical of his quiet wit, in the face of wartime delays, was his topological comment, "It's wonderful how many different shapes the neck of a bottle can take." (Evans, 1976h)

Newman ran his section at Bletchley Park with patriarchal authority but in a democratic spirit in accordance with which his staff were always encouraged to speak up if they thought him mistaken. Having something of the force of nature about him and possessed of considerable intellectual daring, he demanded, and generally got, the impossible both from situations and people. According to Donald Michie, Newman drove his section with "vigour and certitude, seemingly as a vehicle without reverse gear"(Michie, 2001).

Under his leadership originality flourished. The successes of his team, in which he took great pleasure, were not the result of detailed micro-management but came about by finding people in whom he could place his trust and then allowing them to work according to their own judgment. This freed Newman to concentrate on the larger managerial and organisational issues in the service of which he displayed an "unerring sense of direction in a broader-brush landscape of which [his staff] often had no inkling. Over time his persistence towards a perceived goal would fructify in a stunning coup." (Michie, 2001).

An illustrative example of Newman's democratic management style was his famous 'Tea Party' book,

"in which anyone was encouraged to write anything - mainly technical schemes, analyses and suggestions. Additionally one was free to make the entry There will be a Tea Party on .... at ....', and the discussions then 
occurring at the said meeting were minuted, including decisions and action items with report-back dates. If [Newman] were out of town, or for any other reason, unable to attend, he simply had to read the new stuff and abide by it until or unless it was overtaken by new and subsequent decisions." (Michie, 2001).

His tolerance of democracy and debate notwithstanding, Newman was certainly quite prepared to put an end to discussion when it had served its purpose and he had settled on his course.

"People who incline on occasion to be peremptory usually cover up thereby some inner lack of confidence. In Max's case the reverse was true. His confidence in his own judgment (including his judgment of his own strengths and weaknesses) was serene. From such a being, peremptoriness is that of a god. Moreover here was a god who was pro-active in empowering his servants.

Max Newman was an Olympian. Those years supplied fuel and navigational systems for my own life voyage, - and I am sure for many, many others." (Michie, 2001)

\section{Turing seen from the perspective of Bletchley Park}

Turing's personal manner was always more challenging than that of Newman with the result that reactions to him are somewhat varied. Shy and somewhat isolated, Newman recalled that;

“... he emerged rather slowly as an outstanding man and it was this paper that he then wrote about this machine which lifted him into the first rank, as a purely technical mathematician he was not really among the first mathematicians in the world. ... he had this extraordinary idea of a computable function which has been the basis of a great deal of mathematical logic since that time.'(Evans, 1975)

One fairly consistent theme which emerges is of Turing as a kind and thoughtful man who often went to enormous pains to choose Christmas and birthday presents. No-one was in any doubt about his fearsome intellect. Interviewed in 1976, Good described Turing in the following terms

"He was a kindly person I'd say and a very very intelligent person with a depth of thinking. His I.Q. was only about half way up the undergraduate standard and that convinced me that the I.Q. was a measure of speed of thinking and not depth. That single example was sufficient as far as I was concerned. He was very excitable and in discussions he would often prevent you from talking by saying "Ah!" between sentences continually saying “Ah! Ah! Ah! Ah! Ah!”. I don't know if you knew him yourself...”(Evans, 1976h)

From his earliest involvement with computing, Turing seems to have had a clear appreciation that computers could use number to represent something other than quantity. This was by no means as obvious a notion then as it may seem today and, as we shall see later, even von Neumann was slow to appreciate the possibility of computers as anything other than "number crunchers'. Repeatedly at Bletchley Turing discussed ways in which computers could come to 
embody genuine intelligence, and Turing is properly thought of as the founding father of artificial intelligence.

"Turing believed that the embodiment in electronic devices of the fundamental ideas in the mathematics of computation with which he was earlier associated could be used as an instrument for simulating and possibly eventually surpassing the human brain.... I was one of the group of young people who were tremendously inspired by his ideas but the general run of scientists and mathematicians in that community simply regarded this as a rather regrettable aberration in a very fine mathematical brain that was contaminated by this deplorable streak of science fiction!" (Evans, 1976c)

Certainly Turing was, for much of the time, a very difficult man and anecdotes abound of him breaking off discussions and walking away without another word if he felt that the attention of his interlocutor had wandered. This was an aspect of his personality which seems to have become more exaggerated as he got older. There was another side to Turing though, and not everyone found him problematic. As Tommy Flowers recalled:

“... we didn't find him difficult. Probably because we were the subservient people, we were the people who were doing things for him so we didn't get into argument with him. I think that part of his incoherence was due to a speech impediment, or I don't know if it was an impediment in his speech so much as in his mind. I think... his mind was tumbling over faster than he could get the words over and he would go "a .... a... a..." and break off in sentences and sometimes you had to listen very carefully and integrate several sentences before you knew what he was talking about. ...I think that the trouble with a lot of people was that they couldn't listen carefully enough. Well if you listened carefully enough and perhaps put one or two questions he was very coherent... and we got on with him very well." (Evans, 1976j)

\section{The Bletchley Park Experience and Preparations for Post-war Computing Activity}

Presumably nothing could have been further from Newman's mind when he first came to Bletchley Park than that he should within a few years have left forever mathematics at Cambridge and moved to a provincial university, the principal attraction of which was the possibilities it offered to build a computer (Whitehead, 1946). Colossus changed everything and almost as soon as he had seen it in action, Newman began to lay plans to start work on another computer once the war had ended. Once again Patrick Blackett played an important role in shaping Newman's career. The Fielden Chair of Mathematics at the University of Manchester was vacant and Blackett was determined that Newman should put in for the post. Tempting though the prospect must have been, the decision to accept cannot have been simple. Newman's wife Lyn was appalled at the prospect of giving up "Cross Farm \& our cold but wide \& bright skies for the perpetual gloom of Manchester"(L. Newman, 1945) ${ }^{21}$. For a fortnight or so during February 1945 Lyn resisted the move but matters seem to have come to a head on the $24^{\text {th }}$ February when the Blacketts and Henry Whitehead came to stay at Cross Farm. Lyn's opposition lasted another four days but in the end she capitulated.

\footnotetext{
${ }^{21}$ See also (W. Newman, 2002).
} 
"The Blacketts were determined he should come \& Patrick got at that always sensitive place, pride in a husband's career - he said if Max chose to take a back seat in Cambridge still, another would gladly step in." (L. Newman, 1948)

Newman was of course not the only person in the Newmanry sent in an entirely unexpected postwar direction as the result of contact with Flowers' remarkable machine. Donald Michie went on to become a major figure in the emerging field of machine learning, Jack Good and David Rees continued their association with Newman and joined him for a time at Manchester. It is perhaps a little less well known that Henry Whitehead very nearly left Oxford for a chair at Bristol expressly to take advantage of the opportunities to mechanise their mathematics department. He imagined an alliance with the physicist Nevill Mott at Bristol, to mirror that of Blackett's relationship with Newman and which would form the nucleus of joint activities between Bristol and Manchester (Whitehead, 1946). On the engineering side, Coombs, Chandler and Broadhurst all went on to develop computers in the years following the end of hostilities. ${ }^{22}$

By 1945, Turing's post war trajectory was, like Newman's, fairly clear. According to his mother's account, Turing had, for the previous year at least, been discussing

"his plans for the construction of a universal computer and of the service such a machine might render to psychology in the study of the human brain"(E. S. Turing, 1959)

His ideas came together in his 1945 report "Proposed Electronic Calculator",23 which although pre-empted to some extent by the von Neumann's draft EDVAC report (Neumann, 1945) arguably owes nothing to it and goes far beyond it in scope and conception. ${ }^{24}$ Turing's proposed machine was by no means to be restricted to routine calculation as is illustrated by the following list of problems, all but one of which he took to be within its repertoire:

1. The construction of range tables

2. To find the potential distribution outside a charged conducting cube

3. The solution of simultaneous liner equations

4. The calculation of radiation from the open end of a rectangular wave guide

5. The performance matrix multiplication where the terms are polynomials

6. The calculation of the response to given input signals in complicated electrical circuits.

7. It would not be possible to integrate the area under a curve (due to input restrictions).

8. Counting the number of butchers due to be demobilised (working from Army records)

9. Finding the solution for a simple jigsaw problem.

10. From a given Chess position, to calculate all the winning positions for three moves on either side.

\footnotetext{
${ }^{22}$ Coombs and Chandler developed MOSAIC (Ministry of Supply Automatic Computer) and Broadhurst led the development of ERNIE (Electronic Random Number Indicator Equipment).

${ }^{23}$ Available in Carpenter B.E. \& Doron R.W. (1986).

${ }^{24}$ For an excellent discussion see Carpenter B.E. \& Doron R.W. (1986).
} 
This was to be computing in the modern sense. Turing's report thus marks a clear break with the notion of computing as 'number crunching' and points confidently to a conception of the computer as a universal machine.

\section{$\underline{\text { The Manchester Engineers }}$}

Nearly all of the people who played a part in the early development of computers at Manchester had a Cambridge mathematics background in common. The senior figure in this group was Max Newman who taught Alan Turing and David Rees, both of whom went from Cambridge to Bletchley Park where they came into contact with Jack Good - lately of Jesus College. Tom Kilburn and Geoff Tootill, whose wartime service was spent at the Telecommunications Research Establishment, ${ }^{25}$ had also been students of Newman's at Cambridge.

The exception to the rule of Cambridge mathematics was Professor F.C. (Freddie) Williams. A lifelong engineer, and famously disdainful of mathematics, Williams was, when he took up the Edward Stocks Massey chair of electro-technics in 1946, a major figure in Electrical Engineering with a considerable international reputation.

Williams started his university career in 1929 at Manchester's Department of Engineering which he entered on a Matthew Kirtley scholarship and where he graduated in 1932, with First Class honours and as winner of the Fairbairn prize. The following year was spent very profitably working towards a master's degree under the direction of Frank Roberts. Next Williams embarked on what was intended to have been a two year stint with the Metropolitan-Vickers Electrical Company Ltd., as a college apprentice. In the event, he left after just twelve months having accepted the offer of an IEE Ferranti Scholarship to Magdalen College, Oxford.

Williams worked with Eric Moullin at the engineering laboratories and, in 1936, was awarded a DPhil. Then it was back to Manchester to take up the offer of an Assistant Lectureship in his old department. The following few years were extremely productive and resulted in the publication by Williams of around twenty academic papers. It was almost certainly during this period of ferocious activity that Williams first came into contact with computation, and with Patrick Blackett with whom he wrote a paper on an automatic curve follower for the Hartree Differential Analyser (Anderson, 2007). Thus it was that Williams' active involvement with mechanical calculation ${ }^{26}$ actually began somewhat earlier than the others. In 1939 Williams was awarded a DSc by the University of Manchester.

\footnotetext{
${ }^{25}$ For ease of presentation the term TRE (Telecommunications Research Establishment) is employed consistently throughout this piece to refer to an organisation which underwent considerable change during the period under investigation. The detailed actual picture is quite complicated. In 1935-36 the Air Ministry set up the Bawdsey Research Station (BRS) which in 1938 became the first operational ' $\mathrm{CH}$ ' (Chain Home) early warning radar station. At the outbreak of the war, BRS moved to Dundee and was renamed the Air Ministry Research Establishment (AMRE). In 1940, AMRE was moved to Worth Matravers (Swanage) and was renamed TRE. In 1942, TRE moved to Malvern College. After the war, in 1946, TRE was moved to the former HMS Duke where in 1953 it was merged with the Radar Research and Development Establishment (RRDE) to form the RRE. In 1957, RRE was renamed the Royal Radar Establishment. At around the time this interview was recorded in 1976, the RRE ceased to exist as an independent entity when it merged with the Signals Research and Development Establishment (SRDE) and the Services Electronics Research Laboratory (SERL) to become the Royal Signals and Radar Establishment (RSRE). In 1991 an expanded Malvern became a founding member of the Defence Research Agency (DRA) which in 1995 in turn became a division of the Defence Evaluation and Research Agency (DERA). The latest in this long series of changes occurred in 2001 when DERA split into the Defence Science and Technology Laboratories (Dstl) and QinetiQ.

${ }^{26}$ The Hartree Analyser was, of course, an analogue device rather than a digital machine.
} 
Recruited by Blackett, Williams spent the war at TRE where he made important contributions to the electronics of radar, the development of $\mathrm{IFF}^{27}$ and to airborne interception systems. By 1942, Williams had become a very influential figure within TRE and headed a small group whose principal job was to solve problems which had proved beyond the powers of other groups both within the organisation and more widely.

At the end of hostilities, Williams was invited by the Massachusetts Institute of Technology (MIT) Radiation Laboratory to co-edit two of the volumes in their twenty-four volume series on Electrical Engineering. Williams was both literally and metaphorically writing the book on his discipline.

It was in connection with the MIT series that Williams made a couple of visits to the USA in 1945 and 1946 during one of which he saw ENIAC and first learned of attempts to use cathode ray tubes (CRT) for data storage. Williams, whose attention was fixed on radar, took no immediate interest in computation. This changed after he returned to England. As he explained in his 1976 interview with Chris Evans:

"the problem [of computer storage] was quite simply brought to my notice and it was up to me then to either take an interest in it or not take an interest in it. It seemed quite a serious challenge. I knew nothing about any other attempts that were going on to produce storage, so one made a few enquiries of the people who had brought the problem to me and they enumerated, for example, the mercury delay line store as being a possibility. Fortunately for me, I suppose, during my immediately previous visit to the United States, I'd seen some work at the Radiation Laboratory using storage on cathode ray tubes for the purpose of echo cancellation in radar - to record one trace and use that to cancel the fixed echoes in a second trace. Now this had failed, but in the process of doing experiments certain properties of cathode ray tube surfaces had been exposed and they themselves had, I believe, thought, certainly Eckert and Mauchly had thought about the possibility of using cathode ray tubes." (Evans, 1976e)

Williams doesn't say who might have brought the problem of computer storage to his notice but the possibilities are fairly limited. Around the time in question the National Physical Laboratory (NPL), were trying to secure the services of electrical engineers to build the Automatic Computing Engine (ACE) and Blackett and Newman were also looking for engineers to construct a machine at Manchester. Williams indicates elsewhere that he was already active "in the computer field" when first approached by Newman so it was almost certainly NPL who made the initial approach. John Womersley, Superintendent of NPL's recently-formed Mathematics Division, contacted TRE on the $8^{\text {th }}$ May 1946 enquiring about the state of research there into mercury delay lines. The approach was probably made at Turing's suggestion. By the $13^{\text {th }}$ August, NPL had received an encouraging response with Williams indicating a 'strong interest' in the problem of storage. The enumeration of other alternative possibilities for computer storage, to which Williams refers, is likely to have been the same list which Turing gives in the ACE report and from which it was in all likelihood taken. Options mentioned there included

\footnotetext{
27 'Identification - Friend or Foe' which enables radar operators to make the critical distinction between friendly and enemy aircraft.
} 
punched paper tapes (as used in Colossus), acoustic delay lines, electric delay lines, magnetic tape and storage tubes. Turing concludes that:

"Much the most hopeful scheme, for economy combined with speed, seems to be the 'storage tube' or iconoscope (in J. v. Neumann's terminology).

...In an iconoscope as used in television a picture of a scene is stored as a charge pattern on a mosaic, and is subsequently read by scanning the pattern with an electronic beam. The electron beam brings the charge density back to a standard value and the charge lost by the mosaic registers itself through its capacity to a 'signal plate' behind the mosaic. The information stored in this way on an iconoscope, using a 500 line system, corresponds to a quarter of a million digits.

...It seems probable that a suitable storage system can be developed without involving any new types of tube, using in fact an ordinary cathode ray tube with tin-foil over the screen to act as a signal plate.

...None of this involves any fundamental difficulty, but no doubt it will take time to develop" (A. M. Turing, 1946)

Having had storage tubes identified to him as potentially the most attractive combination of speed and economy it is hardly surprising that Williams declined to interest himself in mercury delay lines but preferred instead to direct his considerable skill at making storage tubes a practical reality. Williams was used to tackling the engineering problems that others could not solve and this must have seemed an ideal opportunity to launch his post war career. Williams and Kilburn managed to solve the engineering problems involved in realising this 'hopeful scheme' with commendably little delay.

Tom Kilburn was a convert to engineering. He had started out as something of a mathematical specialist having been allowed, by his headmaster at Wheelwright's Grammar school, Dewsbury, to study almost nothing else from around the age of fourteen. In 1940, Kilburn went up to Sidney Sussex College, Cambridge with a State, a Dewsbury Major and an Open Scholarship. In 1942, at the end of a shortened course, he graduated with First Class Honours in the Mathematical Tripos. During the war, many Cambridge mathematics dons were absent from the university serving at Bletchley Park and elsewhere. In spite of this privation, Cambridge still boasted a lively mathematical community in which Kilburn played his part. As the Sidney Sussex college representative in a sub-group of Cambridge University Mathematical Society known as the New Pythagoreans, Kilburn would almost certainly have come into contact with a number of people who would later go on to play a part in the development of computing. Geoff Tootill $^{28}$ and Gordon Welchman ${ }^{29}$ were, like Kilburn, officers of the New Pythagoreans. Speakers to the student society included future Bletchley Park code breakers M.H.A. Newman ${ }^{30}$, K. J. Le Couteur and W.T. Tutte.

However, one figure into whose orbit Kilburn would not have come was Alan Turing, whose departure to Bletchley Park in 1939 happened too soon for them to have met. Nor would

\footnotetext{
${ }^{28}$ Christ's College representative for the New Pythagoreans and President of the Archimedeans.

${ }^{29}$ Honorary Vice-President. Welchman was also from Sydney Sussex College.

${ }^{30}$ Kilburn and Tootill were also students in classes given by Newman.
} 
Kilburn, whose mathematical inclination was more applied than pure, have been likely to have read "On Computable Numbers" as an undergraduate:

"....pure mathematics seemed extremely abstract. I was the sort of person who was always prepared to accept that two and two are four, whereas I'd spent the first term at Cambridge in one of Newman's lectures proving that this was so. Whilst it was all very interesting - I mean one could appreciate the beauty of it - it left me rather cold. At the end of it, you didn't seem to be much further forward..." (Bowker \& Giordano, 1993 pp.18-19)

In light of his youth when he solved the Entscheidungsproblem, and the sheer magnitude of his achievement, it is not unreasonable to suppose that Turing's name and something of his reputation (if only as a recent Smith's prize winner ${ }^{31}$ ) ought to have been known to someone as active in the mathematical community as Kilburn just as it was to Jack Good (Evans, 1976h). ${ }^{32}$ However, speaking in 1976, Kilburn recalled:

"I know now that Turing published, I believe in '36, a Ph.D. on digital computers but at that time I was fifteen. I'd never heard of Turing until 1947 perhaps.” (Evans, 1976k)

Some time during his last year at Cambridge, Kilburn attended a talk by C.P. Snow ${ }^{33}$ who was visiting universities recruiting people for unspecified war work. As Kilburn engagingly recounts, he had some fairly clear ideas about what he wanted to do for the war effort:

"It seems silly but if I could have joined the RAF as a pilot, I would have done that, but I was relegated to navigator or some such, and that was not quite so appealing. It sounds egotistical but I like to lead. I like to be in charge and I didn't fancy the idea of being driven and crashed by some other character. I wanted to do my own driving and crashing. It's on these sorts of whims that life is founded-it's not through any profound thought is it? You take advantage of what's there at the time." (Bowker \& Giordano, 1993 p.17)

After leaving Cambridge, Kilburn enrolled on a number of short courses in electronics followed by a six-week City and Guilds course on electricity, magnetism and electronics. After a break of around a week, Kilburn was posted to TRE where, as a mathematician, he was not met with unbridled enthusiasm. Williams had requested an extra person to join his team and Kilburn was the person they had sent. The other members of Williams' team were all around 30 years old with an average of 10 years experience in practical electronics. Kilburn was aged just 21 and prior to being called up had not the least interest in electronics or electronic equipment of any

\footnotetext{
31 The Smith's Prize was set up to foster an interest in the study of applied mathematics and consequently should have been of interest to Kilburn - even if only to the extent of being acquainted with the names of recent recipients. For an excellent discussion of the Smith's Prize see Barrow-Green, J., "A Corrective to the Spirit of too Exclusively Pure Mathematics: Robert Smith (1689-1768) and his prizes at Cambridge University”, Annals of Science, 56 (1999) pp.271-316.

32 Even Good, himself a winner of the Smith's Prize in 1940, had not actually read Turing before the war.

${ }^{33}$ Charles Percy Snow, Baron Snow of Leicester. Originally trained as a chemist at Leicester and a physicist at Cambridge, Snow was at the time of this talk, mid way through his four years of service as technical director of the ministry of labour.
} 
kind. Williams was not impressed with the latest addition to his team and made no attempt to hide his disappointment:

“... in effect he said 'Oh God, you don't know anything?' and I said 'No.'. That was the sort of relationship at the start. But of course by the time we left Malvern - that was four years later - the relationship was quite different." (Bowker \& Giordano, 1993 p.18)

In trying to come to a balanced assessment of the contribution made by Kilburn to the development of the first stored program computer at the University of Manchester, the historian is faced with a difficult task. With each of the other principal figures it is relatively simple to trace when they first became interested in digital computation and to discern the intellectual roots out of which their interest grew and developed. Pinning down when exactly Kilburn first became aware of digital computation or first began to think in detail about the design of digital computing machinery is somewhat more complicated. The situation is far from improved by Kilburn's own recollections which actually add to the confusion by appearing to rule out almost every possible account without offering any alternative explanation.

Kilburn stressed in a number of interviews that he was not familiar with the corpus of published work available at the time of the Manchester development. However, an apparent lack of familiarity either with von Neumann's "First draft of the report on the EDVAC" or Turing's "Proposed Electronic Calculator" does not appear to have acted as any sort of impediment to him. Indeed both reports were, in Kilburn's estimation, fairly irrelevant for an engineer:

"All you needed to know... is that the computer has a store which is alterable, that it goes through a program in order, and that it does its computing in an arithmetic unit. You don't need to know anything else. Right? Where I got this knowledge from I've no idea." (Bowker \& Giordano, 1993 p.20)

Nor did Kilburn have any use for the theoretical description of the computer outlined in "On Computable Numbers" or for mathematical concepts in general:

"I'd never read Turing's papers but you don't need, for example, the Turing machine. It's irrelevant. It's a mathematical concept... but not of much interest to me" (Bowker \& Giordano, 1993 p.20)

Kilburn acknowledges that he was aware, around 1945, of the development of mercury delay lines ${ }^{34}$ but does not appear to have had any active involvement in digital computing prior to 1947. Nevertheless he appears to have had, by that time, some very clear ideas on how computer development should take place even if he was less certain exactly how these ideas had first occurred to him:

"Between early 1945 and early 1947, in that period, somehow or other I knew what a digital computer was, I knew how I would build it, and I knew how I wouldn't be building it" (Bowker \& Giordano, 1993 p.20)

\footnotetext{
${ }^{34}$ Presumably this knowledge came via F.C. Williams who, as we have seen, also became aware of these developments at around the same time.
} 
If Kilburn's thinking on computer design was as mature by 1947 as he appears to be suggesting then he gave no sign of it at the time. Certainly Williams appears not to have been aware of anything remotely approaching the suggested level of sophistication in Kilburn's thinking prior to 1948. Indeed, far from believing that Kilburn had already thought out in some detail how to implement a universal Turing machine as early as 1945, Williams recollection was that neither of them knew very much about computers until after they had made substantial progress on the CRT store. Only then, by Williams' account had they reached a point where a detailed understanding of computers was necessary. Williams recalled in 1975, that $\mathbf{i}$ was Newman and Turing who first explained the basics of computation to the engineers:

"With this store available, the next step was to build a computer around it. Tom Kilburn and I knew nothing about computers, but a lot about circuits. Professor Newman and Mr. A.M. Turing in the Mathematics Department knew a lot about computers and substantially nothing about electronics. They took us by the hand and explained how numbers could live in houses with addresses and how if they did they could be kept track of during a calculation. In addition, Professor Newman had a grant from the Royal Society.” (Williams, 1975 p.328)

He repeats substantially the same account in his interview with Christopher Evans:

"Now let's be clear before we go any further, that neither Tom Kilburn nor I knew the first thing about computers when we arrived in Manchester University. We knew that ... we'd had enough explained to us to understand what the problem of storage was and what we wanted to store, and that we'd achieved. So the point now had been reached where we'd got to find out about computers. Now we were very fortunate in this respect because we had in the University here, Professor Newman and $\mathrm{Mr}$ Turing, who were both very keen on computers and indeed Newman had already got a grant from the Royal Society to build a computer but had not in fact yet embarked on the problem of building it, nor indeed was Newman, who was a mathematician, the right sort of person to build the computer. So it was a very fruitful opportunity for collaboration between the Maths Department and the Electrical Engineering Department. And Newman explained the whole business of how a computer works to us, took him, I should think, all of half an hour. So we went away and decided to build one" (Evans, 1976e)

Some questions have been raised over the details of Williams' account (Napper, 1998, Section 2) but it is clear that the general sequence of events outlined by Williams, in which precise consideration of computer design was deferred until the problem of storage had been solved, fits very well with the known chronology of the development of the Manchester Baby. Up until the autumn of 1947 (probably October) nearly all the engineering effort was spent on getting the CRT store working reliably with 2048 bits. During November, Kilburn prepared his progress report "A storage system for use with binary digital computing machines" which was completed by the $1^{\text {st }}$ December. In the last few months of 1947, Kilburn was concerned about thoroughly testing the CRT and, to that end, was beginning to work more seriously on the design of the 
machine. It is possible that there may have been breadboard ${ }^{35}$ construction during the same period.

Kilburn, speaking to Chris Evans in 1976, confirms that no serious attention was paid to working on a computer until after the problem of storage had been solved:

"EVANS So in '46 you came up to Manchester. Perhaps you could start absolutely at the beginning. ... were you immediately told what the nature of the problem was and what the goals were?

KILBURN Well whilst at RRE ${ }^{36}$ some initial work had been done on cathode ray tube storage by Professor Williams ${ }^{37}$ and Ritson and they had succeeded in storing one digit. And it was quite clear what the programme was, we were not immediately busy with the idea of building a computer, we were immediately busy in developing a cathode ray tube storage system which had a very important property over the mercury delay line in that it had what is now called immediate access to information." (Evans, 1976k)

Slightly later in the conversation Kilburn suggests that it was not apparent to him much before the middle of 1947 that a computing machine was going to be built ${ }^{38}$.

“... it was a very exciting time and there were a very small number of people involved who worked together very closely indeed. Put in some very hard and continuous work and we just pressed on, and I wouldn't be able to put a date on it, but by perhaps the middle of ' 47 or slightly earlier it was already apparent we were going to build a computing machine. And I remember writing up, for the purposes of my Ph.D. to be submitted later, a design for the machine which we ... the prototype machine which we built in 1948 and which we reported as working in June 1948. I remember that design being complete by about December '47. So, we rapidly moved from the phase that it was only a store that was the basis of the project to the state where we were certainly going to build a computer."(Evans, 1976k)

While detailed engineering work on the Baby probably did not begin until very late in 1947 or perhaps early 1948 it is clear that the mathematicians had been giving serious thought to the technical specification of the stored program computer for at least the previous eighteen months.

It is also apparent from Good's notes that from the start of 1947 they had been communicating their thinking on the subject to Kilburn. One example of this dialogue and the influence it may

\footnotetext{
${ }^{35}$ A breadboard is a reusable solderless prototype of an electronic circuit generally used for experimenting with circuit designs.

${ }^{36}$ Kilburn appears to have mis -spoken here. He presumably meant the Telecommunications Research

Establishment (TRE) as the Radar Research Establishment (RRE) was not formed until 1953, some years after Williams had taken up his appointment at the Victoria University of Manchester.

${ }^{37}$ Williams filed the first patent associated with the CRT store in December 1946, a provisional patent for the single-bit store.

${ }^{38}$ I am indebted to Chris Burton for clarifying that the actual date was almost certainly around October 1947.
} 
have had may be found in Appendix 1 where a suggested block diagram for the Baby (Appendix 1, Fig.1) drawn by I.J. Good on the $3^{\text {rd }}$ June 1947 is shown. The diagram and a short report were passed in the first instance to Max Newman and David Rees who approved them with only minor modifications. Newman passed Kilburn the material on the $10^{\text {th }}$ June 1947. The precise extent to which the diagram Kilburn included in his report to TRE (Appendix 1, Fig 2) owes an intellectual debt to the earlier work by Good is a matter for just the sort of internalist debate which is very common in the history of computing. The temptation to pursue that line risks obscuring the much greater significance of Good's notes as documentary evidence that the computer-building activity at Manchester was, in contrast to what the dominant historical discourse would have us believe, very much a collaborative effort between two communities of practice out of which a third and distinct community was about to emerge.

\section{The Two-project Myth}

The notion that in Manchester, immediately after the war, there were two distinct and separate projects to build a stored program digital computer, one led by Williams and the other by Newman represents an orthodoxy in British history of computing. From this stance Williams' project is perceived as a triumph and the engineers emerge as heroic figures whereas, by contrast, Newman's project is characterized as a failure and the mathematicians are, if mentioned at all, portrayed as marginal figures. The two-project myth, reflects the dual nature of the computer (Mahoney, 1988) and is a central tenet of a wider professional mythology which has emerged as the dominant discourse in the history of British computing and within it the engineering or practical perspective is privileged while the mathematical or theoretical point of view is almost entirely excluded.

There will not be space here to deal comprehensively with the dominant discourse as a whole or even to provide a full treatment of the two-project myth but a few comments are in order.

An early statement of the two-project myth comes in Lavington's short book "A History of Manchester Computers" (Lavington, 1998).

"Newman and his mathematicians took no active role in the design of Manchester computers, but he did provide a general enthusiasm for the project... In due course [the Newman] project became merged with the Williams/Kilburn machine." (Lavington, 1998 pp.4-5)

The assertion that the mathematicians took no active part in the design process is more complex than may, at first, be apparent and is clearly dependent on what precisely is meant by 'active' and 'design'. Williams' recollection that neither he nor Kilburn knew the first thing about computers until 1947 when Newman and Turing explained to them how a computer works is prima facie evidence, coming from an engineering source, of at least one active contribution made by the mathematicians. As we have seen, Good documented a number of other contributions to the SSEM design process and also recalls having had a hand in the general theoretical education of the engineers.

"I was at Manchester, and concerned with computers, before the engineers F.C. Williams and Tom Kilburn arrived, and helped teach them a few things." (Good, 1945-8) 
Newman delivered, at Manchester in the immediate post war period, a series of lectures on computing which may have helped shape the understanding of the engineers but may at the very least be thought of as constituting part of the ir computing education. Moving outside the immediate Manchester circle, Turing and Wilkinson delivered, at the Ministry of Supply's London Headquarters between late 1946 and early 1947, a series of lectures on the design of the ACE. Kilburn attended these lectures and whatever impact they may or may not have had on the subsequent design of the SSEM, it is clear at least that Turing was, contrary to the impression which may have been left by Lavington, active ly disseminating ideas on computer design. It is certain that as part of his attempt to interest Williams in working on computers - specifically as part of the Royal Society sponsored computing machine project, Newman would have had conversations of a substantive nature with Williams while the latter was still at TRE. As noted above, NPL were also very keen to solicit Williams' help to build the ACE and it is overwhelmingly probable that this would have involved a number of quite detailed exchanges, at least some of which would have involved Turing directly. ${ }^{39}$

It is clear that over and above any detailed computer design work which may have been undertaken by Newman and the Manchester mathematicians before 1948, they were, during the same period, also active in educating engineers to the point where they could engage constructively with the problem of building a computer. Turing, who had mature computer design plans well before the Manchester engineers had even begun to think serious ly about computing, was similarly active in what we might today call knowledge transfer, via the NPL. It is clear that any characterization of the mathematicians as passive enthusiasts runs counter to the available evidence.

Of course, it is one thing to note that mathematicians within Manchester and more widely were active in stimulating an interest in computing per se, but quite another to show that they had a tangible effect on the design of the SSEM. However, there is no reason why anyone should have ever expected mathematicians to be making that kind of contribution. It is one of the shortcomings of Lavington's account that it suggests that active involvement by mathematicians in the detailed circuit design of the SSEM is a pre-requisite for their being full partners in the project. This is very much to see the world from the perspective of the drawing board or the soldering iron and it is important to recognize that what counts as 'activity' is critically dependent on one's point of view.

Consider how the Colossus was developed at Bletchley Park. There, Newman, along with others, took great care to explain to Flowers and the Post Office engineers precisely what was required of the machine which needed to be produced. This would have involved giving an explanation of enough by way of general principle as would be needed to let the engineers make progress. In the case of Colossus, it would also have been necessary to provide detailed explanation of the precise statistical techniques which the machine was to employ and an explanation of the sort of changes in German encryption techniques to which the machine might need to respond during its lifetime. In spite of the general direction in which the flow of information was going, it would be a mistake to see even this stage of the development of the Colossus as involving active mathematicians and passive engineers. It would be more accurate to think in terms of a joint endeavor. Newman, as a mathematician and a cryptanalyst would have had a non-trivial job to draw up the project specification for Colossus while the engineering design and machine fabrication of the device would properly fall to others. The specification for

\footnotetext{
${ }^{39}$ For example, Williams went with R.A. Smith and A. Uttley to NPL on the 22nd November 1946 where they discussed the ACE project with Womersley and Turing. It was this meeting that, in due course, resulted in Kilburn's secondment to Manchester.
} 
Colossus was not contrived in vacuo and Flowers and his team would constantly have been having to triangulate the ideas of the mathematicians onto the geography of the possible. The fact that the skills of a number of different professions needed to be brought to bear on the problem is no demonstration that there were a number of different computing projects at Bletchley Park only one of which, Flowers project, was a success. Similarly, even if it were the case that the Manchester mathematicians had absolutely no involvement in the detailed circuit design of the SSEM it would do nothing to show that there were two different projects in existence, only one of which was a success.

Lavington, who was himself trained as an Electrical Engineer at the University of Manchester in the early 1960s before joining Kilburn's MU5 high-performance design team, based his account substantially, and without further interpretation, on conversations with Williams, Kilburn and Tootill (Lavington, 2005). It is reasonable to suppose that what I have so far been referring to as the Lavington account may be regarded as an accurate representation of the Manchester engineering perspective post-1960.

The account offered, in 1993, by Croarken of the development of the SSEM correctly indicates that Williams' main focus when he arrived at Manchester was the development of the CRT store:

“TRE was willing to continue to support Williams' work on cathode-ray tube storage systems not only by seconding Kilburn but also by supplying Williams with the components necessary for him to carry out his research." (Croarken, 1993 p.14)

But Croarken begins to go slightly astray in characterizing Newman's initial intentions and how his thinking altered after the arrival of Williams.

“In postwar Britain, such components were not readily available. Newman was pleased that Williams had been appointed and decided to wait for Williams' work to come to fruition rather than rely on buying components from the United States whenever they became available. Newman did not anticipate that Williams would produce a working memory unit in such a short time." (Croarken, 1993 p.14)

In fact, Newman, in his progress report on the computing machine project made to the Royal Society on the $20^{\text {th }}$ December 1948 is quite clear that:

"It was originally intended that, in order to have a machine ready for experimental work as soon as possible, one of the types already under construction in 1946 should be copied. However when Mr. F.C. Williams was appointed to the Chair of Electrical Engineering at Manchester in 1946, the design of the machine was naturally placed in his hands" (M. H. A. Newman, 1949 p.14)

So Newman's intention does not appear to have been to buy components ${ }^{40}$ but rather to make use of design ideas developed elsewhere to guide the fabrication of a facsimile (or near facsimile) at

\footnotetext{
${ }^{40}$ This is not to deny certain key components, such as a memory device, might have been purchased complete from outside.
} 
Manchester. It ought, perhaps, to be stressed that this would have constituted a serious intellectual and engineering challenge demanding a high degree of skill and theoretical understanding. The proposed activity would have been more or less on a par with the work of Wilkes at Cambridge. Nor was Newman, as Croarken suggests, only interested in American developments but was prepared to make use of any available design. In support of Newman's plan, Rees was sent to the United States to familiarize himself with the work being done there while Good accompanied Newman on a visit to NPL where Turing explained his ideas for the ACE. Evidently, Newman was not much taken with Turing's lecturing style and quickly returned to Manchester, leaving Good to continue on his own. Close contact was maintained thereafter between the Manchester mathematicians and NPL.

Not only did Newman immediately place responsibility for the design of the Royal Society machine in Williams' charge but it was always his intention to delegate to an engineer the job of producing a detailed computer design. Newman's intention to delegate made it particularly important to find a person with the right balance of skills. Newman needed someone who could grasp the difficult theoretical ideas involved and be able to translate these into circuitry. In his 1946 application for Royal Society funding, Newman put it thus:

"Evidently the success of the enterprise would hang largely on the appointment of the designing engineer. Although he would not be expected to provide the main ideas for projects, he would need a rare combination of wide practical experience in circuit design, with a thorough understanding of the abstract ideas involved. It will be necessary to offer a good salary, up to say $£ 800$, to the right man."

(M. H. A. Newman, 1946b)

After a great deal of searching, it was Blackett who suggested that Williams might be the man for the job (Randell, 1975 p.12). Finding the right person to act as the designing engineer was obviously central to Newman's plans but it was equally important that he be supported by mathematicians whose role it would be to develop and explain the main theoretical ideas which underpin computing. Building a stored program digital computer would require a delicate bringing together of the abstract and the practical. The engineering task would be to render the abstract ideas of the mathematicians into physical reality. While he recognized the value of basic research on the principles of computer construction, Newman had an altogether different purpose in mind for his proposed machine. His conception of the computer was as a device which would lead to the development of new types of mathematical solutions and prompt the creation of new techniques in mathematical analysis. Newman did not see the computer as an end in itself, but as a tool which, if it was worth developing at all, had to do something. Williams' conception was, and always remained, somewhat different as he explained to Chris Evans in 1976:

"I'm an engineer, I defined the computer right from square one as being a device which was designed to facilitate the performance of mathematics, the greater part of which would be very much better not done." (Evans, 1976e)

Williams' appointment did not mark the starting point of an independent computer-building project at Manchester but was rather an important milestone in the engineering of the Royal Society machine. Following Newman's plan, laid down the previous year, different aspects of 
the project were being semi-autonomously managed by different specialist groups. In an echo of the Colossus development, primary responsibility for the machine specification and determination of the final use of the machine fell to the mathematicians. The overall responsibility for the details of implementation belonged to the engineers. This division of labour played to the strengths of the participants and would have made perfect sense to all parties. As Williams told Randell in 1972:

"Since he [Newman] understood computers and I understood
electronics the possibilities of fruitful collaboration were
obvious."(Williams, 1972)

As the initiator of the Royal Society supported computing project and the senior Professor, the overall leadership of the activity started out in Newman's hands. Over time, things changed. Within a few years it became clear that the future direction of the project was likely to be focused on engineering and would, in consequence, be better directed by an engineer. In recognition of this, Newman withdrew from active involvement leaving the field to Williams and Kilburn. Williams, who had little interest in computing, soon stepped back leaving the further development of computers at Manchester in Kilburn's hands. This period of transition marked was very important in the emergence of a new community of practice in Britain - computing and Kilburn was in the perfect position to become one of its leading figures.

Croarken's observation that:

"While the work in the Electro-Technics Department went on independently of the Royal Society Computing Machine Laboratory, the engineers did seek advice from Newman and his staff" (Croarken, 1993 p.14)

can now be seen as somewhat wide of the mark. While it does recognize some role for the mathematicians, it fails to acknowledge the full significance of their contribution or pay sufficient attention to the overall context in which the project was being carried out. The relative independence of the work of the engineers and the mathematicians was, in fact, more apparent than real. Good's notes, the existence of which Croarken seems alone in recognizing ${ }^{41}$, give a tantalizing glimpse of the connections which actually existed between the engineers and mathematicians. They impart a clear sense of an on-going dialogue between people working on different aspects of the same development.

By the time we get to Burton's account of the development of the SSEM (Burton, 2005), the Engineers are cast as entirely independent and, echoing Lavington's narrative, the mathematicians are once again portrayed in the role of encouraging bystanders:

"Although their work in the electrical engineering department was completely independent of outside influence, Williams and Kilburn were nevertheless encouraged by the Mathematics Department's Max Newman, who secretly knew about the Colossus code-breaker machine and was familiar with the work of Alan Turing. Newman wanted a computer in his department and could see that the Williams-Kilburn work might lead to one." (Burton, 2005 p.46)

\footnotetext{
${ }^{41}$ Croarken's account of the development of the Baby is much the best of those considered here.
} 
As we have seen, far from being independent of "outside influence" the engineers were working side by side with the mathematicians developing a specification for the proposed computer. The bibliography of a report submitted by Kilburn to TRE (Kilburn, 1947) also attests to the fact that he, and presumably Williams, were aware of relevant written material pertaining to computing projects outside Manchester. ${ }^{42}$ The idea of the department of Electro-Technics as a selfcontained island of computing activity not only lacks substance but ignores the fact that Kilburn's very presence in Manchester came about only as a result of TRE's concern to retain a helpful connection with the NPL.

\section{The Financial Myth}

The claim that the SSEM enjoyed, from the outset, significant financial support from TRE in contrast to a complete or almost complete lack of financial assistance from Newman and the Royal Society until after the SSEM was complete, may be termed the financial myth.

Lavington sets out the position in a fairly neutral way:

"The Royal Society grant of $£ 35,000$ remained substantially intact for several years, eventually providing for the construction of a building to house the University's Ferranti Mark 1 computer in 1951." (Lavington, 1998)

Croarken spells out matters a little more fully:

"The Royal Society Computing Machine Laboratory housed Williams' and Kilburn's work on a prototype computer being built around the Williams tube store. In reality, the Royal Society Computing Machine Laboratory was a $20 \times 20$-foot room in the Engineering Department, labeled "Magnetism." The laboratory had no staff paid for by the Royal Society. Newman, Good (who left Manchester in April 1948), and Rees were based in, and employed by, the Mathematics Department. Williams, Robertson, and Tootill were on the staff of the ElectroTechnics Department. Kilburn was still a senior scientific officer with the Ministry of Supply. The equipment needed to carry out the research continued to be supplied through TRE. Consequently, the Royal Society grant remained almost untouched." (Croarken, 1993 p.15)

Most recently, Burton highlights how Williams was not a beneficiary of any Royal Society funds.

"Newman's receipt of funds to establish a Royal Society Computing Machine Laboratory was not used by Williams (who was fully funded by the University and TRE), though he later appropriated the name as a tag for the Magnetism Room." (Burton, 2005 p.46)

Napper highlights the important role of the financial myth in supporting the two-project myth:

\footnotetext{
${ }^{42}$ Kilburn refers to unpublished material by Turing and von Neumann.
} 
"There is no question that the "Baby" was Williams' project not Newman's (and effectively funded by the TRE). The confusion is caused because Newman got a grant of $\$ 20000$ capital $+5 * £ 3000$ per year for wages to build a computer from the Royal Society in 1946. Also the room the Baby was built in was called the Royal Society Computing Machine Laboratory. I won't go into the full debate, but in my mind the empirical proof is in the University records, which show that "Royal Society" was stripped from the name after a year or two, and all the capital and the remaining half of the wages in Newman's grant was spent in 1950 on a new building to house the Ferranti Mark I - the 3rd generation of Williams' (and Kilburn's) computers !!" (Napper, 2004)

There are two substantial defects which run through these narratives. First, they generally fail correctly to represent how and where the Royal Society grant was actually spent. ${ }^{43}$ Secondly, they take no explicit notice of the details of Newman's bid to the Royal Society or his estimate of expected costs, thereby ignoring the financial context.

By January 1946, the university had indicated its strong support for Newman's project but made it clear that this did not extend to a preparedness to provide the necessary financial support. At Blackett's suggestion, Newman turned to the Royal Society for assistance. He gave an outline description of how he saw the project progressing. The plan he sketched owed a great deal to his experience leading the development of the Colossus at Bletchley Park. The engineer would first need the problem to be explained in sufficient detail to permit work to begin but it is hardly without significance in the current context that Newman expected the mathematicians to work closely with the engineer thereafter. It is hardly surprising that he hoped to enlist the support of Turing who was, by then, at the NPL, and Flowers who was still at the Post Office:

"The following scheme is proposed. The initial staff should be a circuitdesigning engineer, (full time), and two half-time mathematicians... The engineer, after sufficient preliminary discussions in Manchester to form some idea of the problem, should spent some weeks at Dollis Hill, gaining knowledge of the known techniques in the field. Both he and the mathematicians should also spend some time in the N.P.L. After this there would be a period of some months in which the skeleton design of a machine might emerge. The rough draft would then go to Dollis Hill to be drawn out in detail and the machine would then be made...

There would still remain the assembling of the machine, and getting it running, which would be done in Manchester." (M. H. A. Newman, 1946b)

Newman's approximate financial projections were as follows:

"Estimated costs

Obviously only very rough estimates are possible. The timing is also liable to large variation either way

\footnotetext{
${ }^{43}$ Croarken's account is much the most nuanced and accurate of the narratives under consideration here.
} 
Annual Expenditure

First Year:

Engineer

$£$

Two half-time mathematicians

Office and travel expenses

Second Year:

Engineer

Mathematicians

Half-time computer

Two maintenance men

Four extra maintenance men

(four months only)

Operator (six months)

Spare parts, upkeep of

laboratory, etc.

Subsequent years - .......... - £3000 to £3500”

(M. H. A. Newman, 1946b)

No detailed breakdown of costs is given for the construction of the machine beyond noting that the total cost would be $£ 10,000$ over the first three years and $£ 20,000$ over the first five years. There is no indication that the project was intended to come to an end after the fifth year and in the light of other comments he makes it seems reasonable to suppose Newman saw Manchester as staying at the forefront of computing over the long term.

Newman makes budgetary provision for two half-time mathematicians but makes no allowance for his own salary presumably because felt he could direct the project in the time he had available after his departmental duties were complete. Newman's managerial style, which as we have seen, involved picking very capable lieutenants and giving them freedom to do their jobs without unnecessary interference, would have made this a realistic expectation.

Newman also allowed $£ 800$ p.a. to secure the services of a full time engineer who, with the agreement of Prof. Willis Jackson. ${ }^{44}$ would have been attached to the department of ElectroTechnics. A few months after Newman's bid was submitted, events moved on and Jackson took up the Imperial College London Chair in Electrical Engineering vacated by the retirement of C. L. Fortescue. The departure of Jackson opened the way for his replacement by Williams, ${ }^{45}$ whose appointment, so meritorious on other grounds, also brought a considerable indirect bonus to the project in purely cash terms. Rather than having to be funded out of the Royal Society grant Williams' salary was paid by the University of Manchester but it is reasonable to suppose that his attention would primarily have been directed to the day to day administration and organisation of his department. The second cash bonus to the project came in the form of the services of Tom Kilburn who rapidly became the de facto designing engineer for the SSEM project. His salary (presumably on a par with that of a university lecturer) was fully paid by the TRE rather than needing to be met from Royal Society funds.

\footnotetext{
${ }^{44}$ Willis Jackson was Williams' predecessor as Professor and departmental head of Electro-technics.

45 Jackson's appointment at Imperial was particularly 'fortunate' as someone of Williams' standing could have hardly been tempted to Manchester to take up a less senior post. At that time, the only Manchester department having two professors was Physics where both Hartree and Blackett held Chairs. It is most unlikely that a second Chair would have been created in Electro-technics had Jackson stayed in post.
} 
Kilburn's immediate enrolment on the Turing-Wilkinson lecture course was consistent with Newman's original idea of educating the designing engineer in the known techniques in the computing field by spending some time at NPL.

Whereas Newman had expected to spend $£ 1300$ during the first year of the project to cover salaries he ended up needing only $£ 500$. In addition, approximately $£ 300$ was spent on sending Rees to the Moore School lectures (Royal Society, 1946b). Allowing another $£ 50$ for miscellaneous spending, this would have brought the first year's actual expenditure up to c.£850. TRE's contribution would have been around $£ 500$ for Kilburn's salary and a further $£ 100$ (approximately) in donated components. It is difficult to place an firm cash value on the hardware TRE supplied as it was mostly surplus stock which if it had appeared on the open market would have had a serious effect on prices Consequently, it would almost certainly have been destroyed if it had not been given to Manchester ${ }^{46}$. The department of Electro-Technics contributed some test equipment which they built in-house and a quantity of small consumables from their own stores. Additionally they provided infrastructure e.g., floor space, drawing office facilities, workshop facilities. In total we might nominally value this contribution as being worth $£ 150$.

Newman made no explicit provision for spare parts, or the cost of components during the first year. This may seem surprising at first glance and may be taken as indicating that he did not anticipate making speedy progress or that his intention was to meet the expense from the capital budget. However a more likely explanation is that Newman anticipated being able to draw on a ready supply of components from the Colossus project. In order to establish what would be needed Professor Willis Jackson was accompanied by Newman to Bletchley Park in the summer of 1945. Writing on the $8^{\text {th }}$ August (M. H. A. Newman, 1945), Newman formally endorsed Jackson's recommendation that the material from two complete Colossi, plus "a few thousand miscellaneous resistances and condensers of other machines" should be made unrecognisable and shipped to Manchester. Only the counter racks and 'bedsteads' were to be left intact. A supplemental request that a punch and reader (Creed or Teletype) might also be included "if available", was also made. ${ }^{4 f}$ On the $6^{\text {th }}$ December 1945 , an escorted consignment comprising between seven to nine tons of components was sent from Bletchley Park by lorry (and trailer) arriving the following day at Manchester University where it was met by Newman and Jackson. Indisputably, at least some Colossus components were eventually incorporated into the SSEM ${ }^{48}$ and perhaps also in other Manchester computers. However the real historical significance of this episode transcends any mundane internalist concerns over the precise extent to which Colossi components came to be reused in later developments. Much more important is the mere fact of Jackson's visit to Bletchley Park. Jackson's presence there and his access to Colossi in situ would have needed clearance in advance at the very highest level and conclusively establishes that there was official sanction for Newman to transplant knowledge gained from the Colossus development into the civilian world. This runs counter to much received wisdom and critically undermines a key aspect of the two-project myth I shall return in greater detail to the myth of secrecy below.

During the first year of the project's life Newman spent around $63 \%$ of his estimated budget.

\footnotetext{
${ }^{46}$ I am indebted to Prof. Simon Lavington for bringing this to my attention.

${ }^{47}$ I am indebted to Prof. Brian Randell for drawing this to my attention The original source material is to be found in the National Archives ref HW64/59.

${ }^{48}$ Racks, previously used on Colossus machines, are clearly identifiable in some of the early photographs of the SSEM.
} 
The difference between anticipated and actual spending was entirely the result of Kilburn's salary being covered by TRE whose additional generosity in donating components had no further beneficial effect on Newman's first year projections since he hadn't allowed for them in any case. There is no reason to believe that Newman would not have covered Kilburn's wages had the TRE proved reluctant, since he had allowed for the cost of an engineer and had obtained the necessary funds. It is extremely unlikely that the Royal Society, or any other grant awarding body, would have looked kindly on any attempt by Newman to pay Kilburn's salary when alternative funding had unexpectedly appeared. In fact, it should be said that the Royal Society showed great latitude in allowing the $£ 20,000$ originally intended for capital development to be spent post hoc on a building. It is also worth mentioning that had the Royal Society instead clawed back the capital grant, matching funds would have had to be found from the budget supporting further computer development at Manchester. The Royal Society can reasonably be thought of as major investors in the development of the machines that followed the SSEM. However, despite the financial scale and political importance of the contribution made by the Royal Society to the SSEM and to its successors, the part it played has received little acknowledgement from historians.

What is the origin of the financial myth and what, if anything, does it reveal about the source of the two-project myth? I have tried to present the Royal Society computing project as Newman might have seen it. However, viewed from the perspective of the department of ElectroTechnics it is possible to see things very differently. No funds made their way from the Royal Society directly to the department of Electro-Technics and it might, in consequence, be possible to come to the conclusion that the Royal Society were not supporting financially the development of the SSEM. While this would help motivate one half of the financial myth it would give grounds for the other as it is equally true that no funds were received from the TRE into Electro-Technics unless some notional allowance is made for components supplied by TRE and used to support project work being undertaken by a Ph.D. student in the department.

If the finances of the project are viewed from the personal perspective of Kilburn, the resulting picture looks remarkably like the financial myth. As a Ph.D. student, Kilburn would presumably have had little detailed appreciation of financial arrangements not directly touching on him. Kilburn would, presumably, not have been aware at the time that the salary costs and travel expenses of staff from another department were being paid for out of Royal Society funds.

Indeed, even if the arrangements had been known to him, it is easy to imagine how this might not have appeared as constituting a meaningful contribution to the work on which he was personally engaged. Furthermore, no-one in Electro-Technics is likely to have taken a markedly different view.

In fairness, the arrangements put in place by the university for effecting payment from the Royal Society grant to the SSEM project were hardly straightforward. For example, the salaries of Good and Rees were not paid directly from Royal Society funds but were 'back-filled'. Thus, the costs were borne, in the first instance, by the mathematics department which was subsequently granted leave to employ a replacement full-time member of staff, the salary being met out of the Royal Society grant. ${ }^{49}$

While the financial contribution of TRE was, from the point of view of university, merely nominal departmental or project funding it was, by contrast, very important from Kilburn's

${ }^{49}$ I am grateful to Mary Croarken for bringing this point to my attention. 
perspective. TRE were directly paying Kilburn's salary and providing components on which his work was dependent. In these circumstances, it was entirely reasonable that Kilburn should think of the support of the TRE as being more important than any other assistance. In October 1948, Kilburn's salary started being paid out of Royal Society funds, but by then the SSEM was already up and running and the future of the development was not in doubt. So, by the time Kilburn might have perceived himself as a direct beneficiary of Royal Society support, it could all too easily have appeared, as Napper puts it:

"That 'Professor Newman had a grant' was true, but in effect it was not used until it was not required.” (Napper, 1998)

This bald statement of the financial myth describes a perspective which is unique to Kilburn and it is his viewpoint alone rather than the departmental or project perspective which is privileged in the financial myth.

\section{Contextualizating the Two-project Myth}

One of the principal defects in the account suggested by the two-project myth is that it ignores the wider context in which Newman, Williams and Kilburn were working. As has been noted already, Williams' predecessor Jackson, had already expressed an interest in the Royal Society Computing Project and had offered "to have the electrical staff on the strength of his laboratory" (M. H. A. Newman, 1946b). Certainly Williams had his own agenda and interests but when he arrived at Manchester he was not operating in a vacuum. The Royal Society award had marked out Manchester as an important centre for the development of new technology. Such a large grant from so prestigious a source would, presumably, have carried great political significance within the University and it would outside. Consequently, there would have been considerable pressure on Williams to continue Jackson's policy of supporting Newman's Royal Society project even if he had personally been disinclined to do so. Indeed, Williams' attitude to the project is just the sort of issue which his appointments panel, may well have explored during interview. Had the panel generally or Newman and Blackett in particular got any sense that Williams intended to set up a rival computing project in the department of Electro-Technics it is extremely unlikely they would have supported his appointment.

In fact, Williams had no interest in developing computers as such. He was focused on the narrower engineering challenge presented by the CRT store and, as we have seen, was perfectly happy to acknowledge an almost complete ignorance of computing per se. It would have been much to Williams' advantage to be seen to be contributing to a large externally-supported interdepartmental project particularly as such an involvement would have given his own work a greatly enhanced significance and would have served greatly to improve his political stock at the University. Working relatively independently on the engineering side of Newman's project gave Williams the advantage of an alliance with Blackett and Newman, opened up a useful source of ideas and intellectual assistance courtesy of the mathematicians and provided a guarantee of financial support for his work, should he have needed it.

By contrast, setting up a rival project would have represented a high-risk strategy - even assuming that the University would have been prepared to let him embark on it. By dividing the intellectual resources available at Manchester he would have lessened the chances of either project succeeding and almost certainly alienated Blackett, Newman and the Royal Society. Williams would have realized that even had a rival project been entirely successful there would 
have been nothing gained which could not have been achieved at far less political risk by working within the Royal Society context. Failure would, of course, have left him very exposed.

The two-project myth implies that Williams was prepared, immediately on appointment, to jeopardize his position by instigating an independent computing project. No plausible explanation is offered for his alleged behaviour. It is only by decontext ualizing Williams' supposed actions that they can be made to appear reasonable. However, once Williams is placed back in the correct historical context, the notion of his setting up a second computing project in Manchester looks a much less credible, as in consequence, does the two-project myth itself.

\section{Post-war Knowledge Transfer}

In 1975, Donald Michie, a member of Newman's section at Bletchley Park, made the tantalizing suggestion that:

"An enormous amount was transferred in an extremely seminal way to the post war developments of computers in Britain. It wasn't appreciated that the transference was taking place and people, say at Manchester, who listened to Newman's early post war lectures on the possibilities of computing and on computer design were quite unaware that this was based on an earlier period of systematic war work but as to the transmission, this transmission was very real and on quite a large scale ....

Newman set about quite deliberately and consciously for a period of years to see that what had been learnt was enabled to be transplanted and should flourish in the environment in Manchester over which he had very considerable influence as a very much respected senior Professor of Mathematics... “ (Evans, 1976c)

It is certainly clear that the fundamental abstract ideas of which the Manchester Baby was the earliest physical embodiment were developed by Alan Turing around 1935-6. Fully aware of Turing's ideas, and perhaps partly instrumental in inspiring them, Newman led the development of the world's first working electronic digital computer in conditions of great secrecy at Bletchley Park. It is also apparent that Colossus changed forever the lives and careers of many of the people who encountered it and a number of them became involved, directly after the end of hostilities, in projects intended to produce stored program digital computers. Association with Colossus appears to have engendered, in a key group of people a new research agenda, which Mike Mahoney correctly characterises as an agreement about what ought to be done:

"a consensus concerning the problems of the field, their order of importance or priority, the means of solving them, and perhaps most importantly, what constitutes a solution" (Mahoney, 2002)

One of the priority-enabling tasks in which they were engaged was spreading the main ideas of digital computing. These were, in essence, a more accessible explanation of the theoretical insights developed by Turing combined with the practical insights gained developing and using Colossus. There is indisputable evidence of an active process of knowledge transfer of abstract 
ideas tempered by practical experience derived at Bletchley Park into civilian computing projects.

\section{The Myth of Secrecy $^{50}$}

In the course of this paper I have looked in some detail at what I have called the two-project myth and the financial myth. A third myth, both more widespread and better founded than either of the others is the myth of secrecy, according to which Colossus, although chronologically the first working electronic digital computer was completely without influence in the development of the stored program computer because it was kept a closely guarded secret.

It is certainly true that the work of the Bletchley code breakers was highly classified. No-one working at Bletchley was allowed, without permission, to discuss their work with anyone working in another hut, much less outside. It is also true that great priority was attached to ensuring that no detailed word of the techniques employed to crack enemy codes should leak out. Indeed, the Germans were not even supposed to know that their traffic had been intercepted, let alone deciphered and read.

However, there was no general restriction placed on divulging generic scientific knowledge acquired at Bletchley. An example of this is Good's treatise on probability (Good, 1950) which was based in its entirety on work carried out jointly with Turing at Bletchley and used routinely both in Enigma and Fish work. Nothing about Bletchley appears in the published version and the unique Bletchley nomenclature e.g., "decibans" ${ }^{, 51}$ is replaced by other terminology.

Newman must have interpreted the existence of a computer at Bletchley as 'generic scientific knowledge' because he was prepared to speak of it although he quite circumspect in how he expressed himself. Writing to von Neumann in 1946, Newman revealed not only that his interest in computers went back to 1943-44 and was independent of any American efforts but that he had some personal experience of computing gained in the context of his war work the details of which were classified. Interestingly, he indicates a preparedness to speak more freely in person than he may write in a letter:

"My more particular reason for writing at the moment is computing machines. I have just heard through Hartree, that you are starting up a machine project in Princeton. I am also hoping to embark on a computing machine section here, having got very interested in electronic devices of this kind during the last two or three years. By about eighteen months ago I had decided to try my hand at starting up a machine unit when I got out. It was indeed one of my reasons for coming to Manchester that the set-up here is favourable in several ways. This was before I knew anything of the American work, or of the scheme for a unit at the National Physical Laboratory. Later I heard of the various American machines, existing and projected, from Hartree and Flowers.

... I don't expect to get started, even on paper, in less than a few months, and then the first thing will be for whole unit to try and learn something in detail about what has already been done. I am of course a complete

\footnotetext{
${ }^{50} \mathrm{I}$ am very greatly in the debt of Donald Michie for patiently explaining the precise nature and extent of the secrecy restrictions placed on BP personnel. This section owes much to Donald's tutelage.

${ }^{51}$ The units by which $\log$ odds were measured.
} 
beginner, though I have had certain relevant experience. What I should most like is to come out and talk to you (for one thing I am still a bit cramped in discussing the past, and I have to ask you not to put 2 and 2 together too accurately, and not to pass it on if you do.) I don't see much prospect of raising the wind for that yet, but something might turn up later." (M. H. A. Newman, 1946a)

Given the general constraints placed on talking about work undertaken at Bletchley, it must be assumed that Newman was absolutely confident that it was permissible for him to talk, in suitably decontextualised ways, about his experience of electronic digital computing. It has already been noted that, in 1945, Newman accompanied Jackson to see the Colossi in situ and from this I have inferred that Newman must have been acting with official sanction. Newman also discussed some aspects of the Colossus with Williams who, understanding from Newman exactly where they had come from, used (at the very least) some recycled Colossus racks in the SSEM (Randell, 1975).

Background evidence of the enthusiasm of the authorities to see the most advanced techniques utilised in peacetime developments can be found in a DSIR Interdepartmental Technical Committee Report produced in 1944 which found there to be a strong case for a Central Mathematical Station which would:

“(1) Undertake research into new computing methods and machines.

(2) Encourage the development of new computing methods and instruments and the dissemination of knowledge of them and of existing methods." (Report of Interdepartmental Technical

Committee on a Proposed Central Mathematical Station., 1944)

The committee had representatives from the NPL, the Admiralty, the Ministry of Supply, the Ministry of Home Security, the Ordnance Survey Department and the War Office as well as the Department of Scientific and Industrial Research (DSIR) itself. That such a group were keen to see the latest developments disseminated suggests strongly that a climate existed in which a controlled knowledge transfer from Bletchley to post war computing projects would have been supported.

By the time that Newman applied to the Royal Society for a grant to support his proposal to build a computer at Manchester it was possible to him to reveal in writing that:

"We have on the staff mathematicians (besides myself) who have acquired an interest and relevant experience in these problems during the war.

...Some fast electrical counters and other equipment have been loaned to me by a Government Department, in case they should be of use for this project, and are now in Manchester.

...The Post Office Research Station at Dollis Hill, with which I was fortunate in making contact during the war, are also interested in the project.” (M. H. A. Newman, 1946b) 
It may have been possible to infer, on the basis of Newman's comments, that the Post Office research station at Dollis Hill, Newman himself and others now in the Mathematics department at Manchester had wartime experience touching on digital computing. Much more importantly, Newman was also sending a clear signal that there was government support for the transfer of the experience gained during the war to utilised in the proposed development at Manchester.

A sub-committee of the Royal Society was formed to advise on the merits of Newman's proposals. It comprised Patrick Blackett, Douglas Hartree, Sir Charles Darwin, William Hodge, and Henry (J.H.C.) Whitehead (Royal Society, 1946a). Apparently, as part of the process, Hartree may have been taken to see a Colossus in situ at Bletchley Park (Kahn, 1976) ${ }^{52}$.

In giving their support to Newman, the Royal Society made the following observation:

"The committee considers that NEWMAN himself, because of his mathematical background and wartime experience, is particularly well qualified for directing this project."((Royal Society, 1946c p.69)

In summary, it may said that Newman was prepared to discuss, in a carefully decontextualised way, the existence, and probably some aspects of the design, of a digital computer developed during the war at Bletchley Park. He was prepared to indicate that he and others in his department at Manchester had personal experience of this machine. He was prepared to indicate that some aspects of the development were subject to secrecy restrictions which could have been inferred to include the use to which the machine was put. The authorities sanctioned Newman's limited disclosure and actively facilitated the transfer of computing knowledge gained at Bletchley into (at least) the Manchester SSEM development. The extent to which other early British computing projects were also assisted and the means by which this may have been accomplished is a fascinating subject but one which falls outside the scope of the current discussion. While it is true that there was a great deal of very effective security surrounding the work which took place in Bletchley Park it would be a mistake to think that this served to prevent Colossus being influential in the development of computers in peace time Britain. Indeed, there is reason to believe Michie's claim that Newman was engaged in knowledge transfer is only one aspect of a larger story of knowledge transfer implicitly, and perhaps explicitly, supported by the government.

\section{The Direct Influence of Turing's Work and the Assessment of his Peers}

There are two main routes by which Turing may have influenced directly the early development of computing: either by his writing or through his personal involvement with people and projects. Turing's 'On Computable Numbers, with an Application to the Entscheidungsproblem' is almost universally thought of today as being the single most important paper in the history of computing. As D.W. Davies put it in 1975:

"Well, I think his discovery ... was really greater than that of Babbage or of Princeton University or von Neumann or anybody. Because the...I mean, von Neumann's contribution at this stage was a particular kind of

\footnotetext{
${ }^{52}$ Good's unsupported account of a visit by Hartree, which might otherwise seem questionable, is given support by the well-documented visit of Jackson to see and, presumably examine in some detail, the Colossi in 1945.
} 
machine architecture which has served us very well but it was only one of many which would have worked equally... equally well. Turing produced a key idea on which every stored program machine was based. I think probably computer scientists generally haven't understood or appreciated the depth of Turing's contribution, partly because it's in unfamiliar language and it doesn't correspond exactly to any of the concepts that have grown up since" (Evans, 1976d)

Jack Good echoes this theme:

“...his original work about 1936 is regarded as quite fundamental. The notion of a Turing machine was an especially useful idea in mathematical logic and the foundations of mathematics because it made the concept seem so much more concrete to have them expressed in terms of exact mechanical processes instead of just formal logic which is rather tricky. ” (Evans, 1976h)

Good's is a judgment uttered in retrospect, for while he knew of Turing by reputation at Cambridge he had not read his work. (Evans, 1976h)

Turing's paper was published in the Proceedings of the London Mathematical Society and was targeted at, and would have been read by, mathematicians. Newman would, of course, have been intimately familiar with Turing's work and possibly his thinking was shaped thereby in ways which turned out to be very productive in the Bletchley Park context. However it would be a mistake to think that Newman, when drawing up the specification for Colossus, was consciously attempting a direct implementation of Turing's thinking. The debt owed to Turing's ideas seems clear when looking from the perspective of the early $21^{\text {st }}$ century, but according to Newman, at the time:

"I think we were not conscious of any dependence on those - I think it's a bit far fetched you know, because the main idea of... Turing ... that you must put in something which tells the machine to do one thing if the answer is 0 and another if the answer is $1 \ldots$ we didn't have that you see." (Evans, 1975)

It has already been remarked that von Neumann probably became aware of the Entscheidungsproblem paper no later than the summer of 1938 and, like Good, considered Turing to have been responsible for the fundamental conception of computing. However, while we may feel confident that von Neumann was influenced by Turing's work it is more difficult to be quite certain about the precise extent and nature of the influence.

Discerning a direct line of influence from Turing's writing to the engineers is even harder to establish. Responding to Chris Evans' question about the effect which Turing's Entscheidungsproblem paper had on the scientific world at the time of its publication, Newman was fairly sceptical:

"I should say practically none at all. I don't think the engineers at that time were reading the kind of periodical that it came out in and Turing himself, right from the start, said it would be interesting to try and make such a machine but he realised, of course, that it would operate, if it was 
made like his design, so slowly, that it would have no relation to any practical problem." (Evans, 1975)

Tommy Flowers acknowledged Turing's influence but in that case it was more as a result of personal contact than through familiarity with Turing's published work:

"I was introduced to the... to the working people, the first of whom was Alan Turing and Alan Turing had the reputation of being practically incoherent in explanation. The astonishing or interesting thing was that we never had any difficulty. I think perhaps we could talk the same language, I am not a very good mathematician but some of the other people were better and Turing was anything but an engineer but somehow or other we could talk to one another and he could tell us what he wanted and we could tell him what we could do. ... the rapport was really quite remarkable. We never seemed to get at cross purposes and we always seemed to understand one another. I don't know why but... that did happen" (Evans, 1976j)

Another of the Bletchley Park engineers, A.W.M. Coombs recalled later that:

"Turing was the guiding light. Turing was a brilliant mathematician but he was a rotten engineer you know. His ideas for making the machine, the engineering ideas, God help us! that machine would never have worked if they'd tried to use those but he was brilliant as a philosopher and a mathematician and... as a seer of the future but not as an engineer" (Evans, 1976a)

The characterization of Turing as an engineer of questionable ability is also offered by A.D. Booth:

"I mean to put it crudely, he was a brilliant man but he had got very eccentric ideas about engineering as I happen to know and I mean this is fact, He wanted to run mercury delay lines using a thing called a supragenerative amplifier as the recycling amplifier. Now anybody who has anything to do with supra-generative amplifiers will realise that it is the last thing you could ever use as it simply wouldn't work and this was one of the causes of trouble." (Evans, 1976b)

However, despite not being a trained engineer, Turing had, earlier than anyone else in Britain, some very clear ideas on how to build an electronic digital stored program computer. As Mike Woodger remembered:

“... it's quite astonishing now looking back on it to see how highly developed his notion was of what he had to do at NPL. In fact, before he even knew he was coming to NPL he had been drafting the design of an electronic computer since he knew of electronics at Bletchley Park during the war and his code breaking activities and he already had pretty clear ideas in his mind as to how to go about it, how big it would be not yet what the storage media... medium would be. That was the big 
gap but he had drafted several preliminary designs for such a machine which he numbered later on versions 1 to 5." (Lavington, 1976)

Despite generally having a poor reputation in the area, Turing's engineering insight was often very great. F.C. Williams famously used the 'regeneration' princip le' as the theoretical basis on which the CRT store was founded. The process involves storing binary digit in the form of an electrical charge on the phosphor screen of a cathode ray tube. Due to the tendency of the charge to leak away it was necessary to arrange matters so that the charge was read and quickly rewritten (regenerated) in order to preserve the information over usefully long periods of time. This process represented a brilliant insight but, as Hodges noted in 1992:

"No-one at the time or since seems to have noticed that [Turing] thought of it earlier, just one example of the refusal of people to believe he could do anything practical." (Hodges, 1992 p.558)

History favours winners and had NPL taken advantage of the lead which Turing had given them and pressed ahead rapidly with the construction of the ACE it is entirely probable that Turing would today enjoy a considerably greater reputation as an engineer than is actually the case. Turing's computer design ideas, quite a few of which were workarounds necessitated by the limitations of acoustic line delay memory, were certainly very interesting and his design produced the very best performance possible within the severe limits imposed by the technology.

Wilkinson goes some way to explaining why Turing, often so much in advance of his contemporaries, was not appreciated as much as he should have been:

"Turing was perhaps the most distinguished person that we have had at the Lab during my time, a brilliant brain but not a very easy man to collaborate with and also his plans for the ACE were very ambitious. He wanted to build a very large computer and I don't think he would have ever agreed, or wholeheartedly supported the construction of such a small machine.... Turing was head and shoulder above us all, I mean he was a great genius perhaps a genius of his type was not what you wanted at that stage in the game." (Evans, 1976i)

Huskey's assessment of Turing is both generous and reflective:

"Turing, he is in a different class and I think that if I could place myself back in that position, you see, I think we didn't appreciate him as much as we should have. We certainly recognised his ability and respected the things he could do and he was a very high powered mathematician so for example, if a question came up about how a delay line work or something, he would write down the equations and work it out mathematically and say this is what it would do you see. Well, we weren't that sure about whether his equations really represented that delay line properly or not so I think we weren't really comfortable with his answers to some of these questions but there was no question about his ability and if we just had faith about the connection between his theoretical capability and the real physics of the delay line, or whatever it was, then we would have been probably even more respectful than we were." (Evans, 1976f) 
The balance of the evidence available suggests that Turing's 1936 paper, considered so important today, had almost no readership among contemporary engineers and, in consequence, had little or no direct effect on their thinking when it came to the development of digital electronic stored program computers. ${ }^{53}$ There is little reason to believe that even the Colossus owed anything directly to "On computable numbers". None of the Post Office engineers who, at the suggestion of Newman, came into contact with Turing's Entscheidungsproblem paper could make much of it and neither they nor the mathematicians who had read Turing had his ideas knowingly at the front of their minds nor were they trying to implement a Turing machine. In the United States, Turing was read by von Neumann but there is little hard evidence concerning the nature and extent of any effect produced in his thinking thereby.

By the time Turing was appointed as a Reader at Manchester ${ }^{54}$ there was little scope for him to influence the design of the Manchester machine in any direct way, but in light of the discussion above, Kilburn surely went too far when he suggested in 1975 that "the mathematics group, I think they would agree, contributed very little [to the design]” (Evans, 1976k)

Turing did have some direct impact on the course of British post-war computing. His ACE report of 1945 was read or its contents were communicated directly to a wide cross-section of the engineers working on the development of computers in the immediate post-war period. The series of lectures which he delivered with Wilkinson at the London headquarters of the Ministry of Supply were initiated because it was considered more efficient that he deliver a course to a large group rather than continue the process of explaining his ideas to individuals (Womersley J.R. 1946). The MOSAIC, built by Coombs and Chandler came about directly as a result of these lectures although Wilkes and Kilburn, who also attended the lectures, appear not to have found them valuable. We have already seen how Kilburn later recalled that before attending the course he already knew how to build a computer. However, it has not been possible to independently verify this suggestion. Wilkes, who had already attended the Moore School lectures and come back with clear ideas on how to go about building a computer, had a more particular and very well founded concern:

"[Turing] outlined his ideas for the logical design of the Automatic Computing Engine (ACE), as the NPL computer was to be called. These ideas were quite different from anyone else's. If sometime in 1950, a new and superior type of memory had suddenly appeared either in Manchester of Cambridge, then it would have been possible - with somewhat of a struggle, since all digital engineering involved a struggle in those days - to connect it in place of the CRT or mercury memory. In either case the interface between the memory and the rest of the machine was such that the programmers would have known no difference. Not so with the ACE, which was predicated wholly on the mercury memory around which everything was built. The programmer juggled with a set of tank numbers and timing numbers in order to get pulse trains representing the various numbers to come together at the right place and be in step. It was entirely in accordance with Turing's turn of mind that the programming for such a computer should have involved a knowledge of the way that the hardware was organized.

\footnotetext{
${ }_{54}^{53}$ Obviously the ACE and its derivatives must be excepted from this comment.

${ }^{54}$ October 1948.
} 
I did not believe that computers would develop along the lines that Turing was advocating, and for this reason I stopped going to his lectures" (Wilkes, 1985 p.136)

To the extent that Turing was influential he was so mostly by indirect means. His ideas, which were directly unknown to almost all of those who might have profited by them and considered incomprehensible to most of the rest, needed to be mediated by others in order to be useful. In this capacity the role of Max Newman crucial. From the outset, Newman was involved in helping shape Turing's ideas and was instrumental in many aspects of Turing's professional life Fully aware of Turing's ideas as expressed in "On computable Numbers" Newman went on the lead the development of the Colossus at Bletchley Park. Deeply affected by the possibilities opened up by the world's first working electronic digital computer, Newman and a small group of like-minded mathematicians, physicists and engineers conceived the idea of building storedprogram computers - universal Turing machines - in the peace time context. It was Newman who, with Blackett's help, secured the backing of the Royal Society to build at Manchester what would turn out to be the first electronic digital stored-program computer. It was Newman and Blackett who brought Williams and, through him, Kilburn into the project. It was Newman who took on the bulk of the computing education of the Manchester engineers that put them into the position to tackle the construction of the SSEM and two young mathematicians from his department Jack Good and David Rees made contributions to the logical design of the machine and must be considered instrumental in its final success. Newman conceived of building a stored program computer while he was still at Bletchley Park and this led, by the route I have indicated, to the development of the Manchester Baby.

While the conception of the Baby may thus be traced back to Bletchley Park it was by no means a one-man effort. The Manchester machine was a by-product of the theoretical genius of Alan Turing and the embodiment of principles enunciated by him in 1936. However it would not have come about without the drive and skill of Max Newman. The role of Patrick Blackett has been alluded to on a number of occasions during this paper and his contribution to the development of computing in Britain after the war warrants careful study. On the implementation side, the contribution made by Freddie Williams in developing the CRT memory was absolutely crucial and the accomplishments of Tom Kilburn were, if anything, even more important. The development of the SSEM was a team effort involving many people by no means all of whom have been mentioned in this paper. The words of Herman Goldstine, made in the context of the ENIAC project, would have equal applicability here:

"I think that if one were trying to be impartial about it he would just have to distribute credit to the whole group. I've mentioned or alluded to the fact that there was a lot of controversy about who did what but... there's really about an infinite amount of credit to be distributed and therefore everybody who contributed, I think, did a remarkable job." (Evans, 1976g) 


\section{Acknowledgements}

I should like to thank Janet Delve and Jeff Paris for their tireless work organising the Turing 2004 conference and the often Herculean efforts they have made as editors for the proceedings.

Thanks are also due to the University of Manchester, the British Society for the History of Mathematics, the British Logic Colloquium and the British Computer Society for the support which they lent to the Turing 2004 conference

I would like to acknowledge the support of the Masters and Fellows of St. John's College, Cambridge in the creation of the Newman Digital Archive (http://www.cdpa.co.uk/Newman/) documents from which played an invaluable part in the preparation of this paper.

My contribution owes much to the family of Christopher Riche Evans, the National Physical Laboratory (Teddington) and the Science Museum, London who have generously permitted me to make extensive use of the quite remarkable series of interviews which Chris Evans' conducted with leading pioneers of computing.

I am hugely indebted to Janet Delve, J.V. Field, Mary Croarken, Ivor Grattan-Guinness, Donald Michie, Brian Randell, Jim Reeds and Doron Swade for their many insightful and helpful comments on draft versions of this paper.

I am further indebted to William Newman, Jack Good, Harry Huskey, J.A.N. Lee, Martin Davis, Andrew Hodges, Chris Burton, Hans Pufal, Brian Napper, Martin Campbell-Kelly, Jonathan Harrison, Clara Anderson for their help.

I should like to express particular gratitude to Donald Michie whose assistance, patience, inspiration and exigency served greatly to inspire and enhance not only this work but my research more widely.

In 2005, Professor B.J. Copeland, who has for many years served as a sounding board for my ideas, received, read very meticulously, but did not make detailed comment on a near-final draft of this paper. 


\section{Appendix 1 Early Block Diagrams}

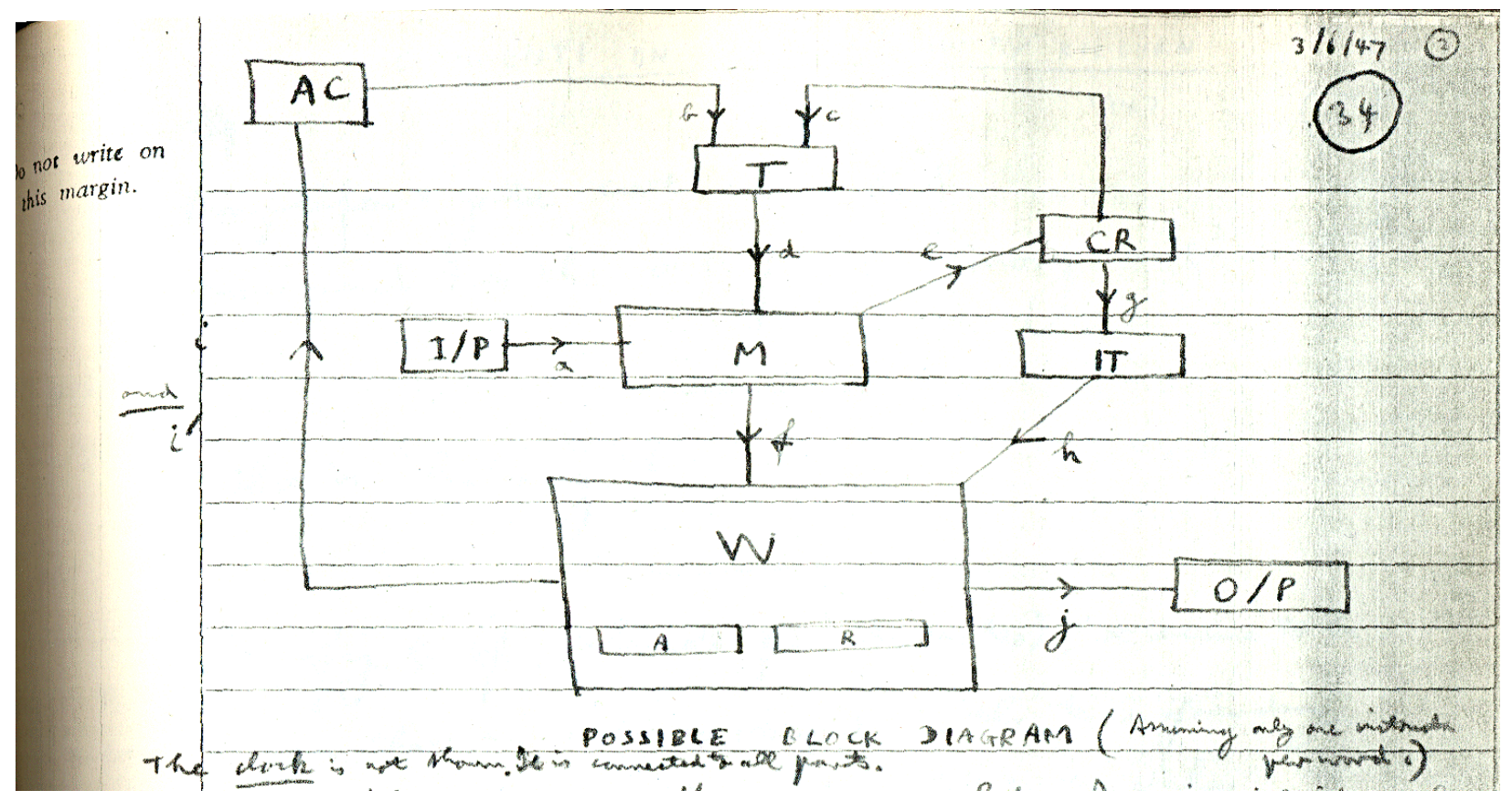

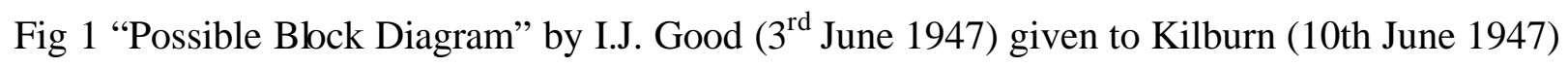

AC Act Counter. (Contains the address of the current or next instruction)

$\mathrm{T} \quad$ Tree (for the memory). Operated by 12 inputs and having 4096 outputs

CR Control Register. Contains one-word instruction

I/P Input

M Memory

IT Instruction Tree. For interpreting the code numbers of different types of instructions

W Works. The circuits which perform the possible types of instruction.

A Accumulator

$\mathrm{R} \quad$ (Arithmetic) Register

$\mathrm{O} / \mathrm{P} \quad$ Output 


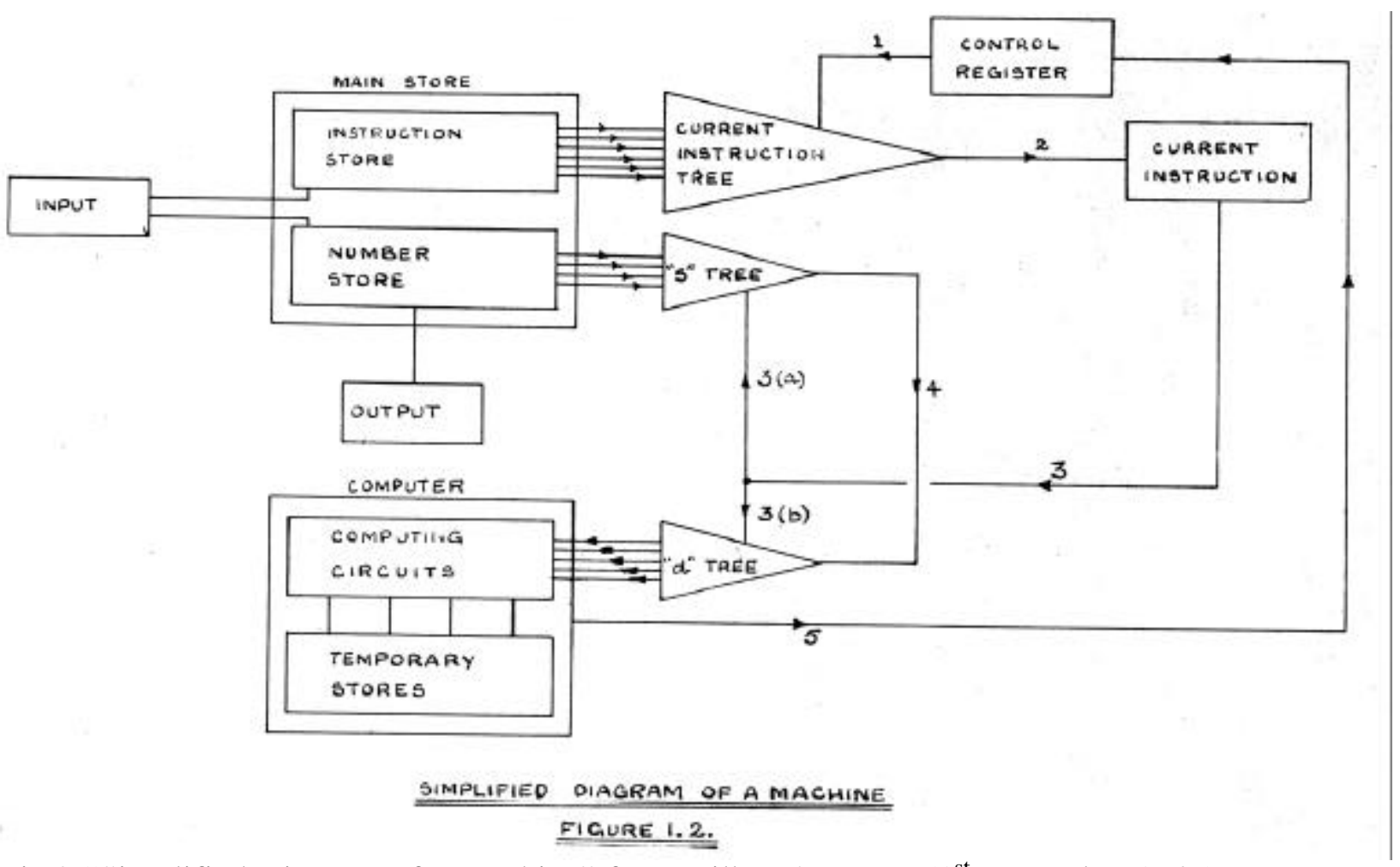

Fig 2 “Simplified Diagram of a Machine” from Kilburn's report ( $1^{\text {st }}$ December 1947)

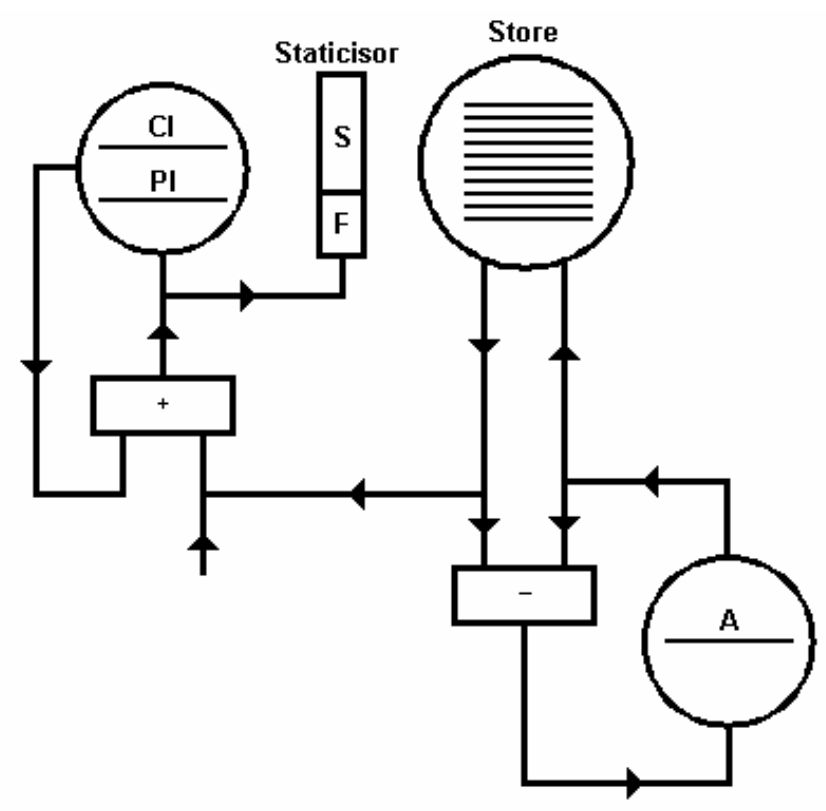

Fig 3 “The Baby as built” Courtesy of Hans Pufal 


\section{References}

Anderson, D. P. (2007). Patrick Blackett: Physicist, Radical, and Chief Architect of the Manchester Computing Phenomenon. IEEE Annals of the History of Computing, 29(3), 82-85.

Banks, D. L. (1996). A Conversation with I. J. Good. Statistical Science, 11(1), 1-19.

Barrow-Green, J. (1999). A Corrective to the Spirit of too Exclusively Pure Mathematics': Robert Smith (1689 1768) and his Prizes at Cambridge University. Annals of Science, 56(3), 271-316.

Blackett, P. M. S. (1942). Letter to John Godfrey Director Naval Intelligence.

Bowker, G., \& Giordano, R. (1993). Interview with Tom Kilburn. IEEE Annals of the History of Computing, 15(5), 17-32.

Burton, C. P. (2005). Replicating the Manchester Baby: Motives, Methods, and Messages from the Past. IEEE Annals of the History of Computing, 27(3), 44-60.

Cambridge University Reporter. (1939).

Church, A. (1936). An unsolvable problem of elementary number theory. American Journal of Mathematics, 58, 346-363.

Church, A. (1937). (in Reviews) On Computable Numbers, with an Application to the Entscheidungsproblem. The Journal of Symbolic Logic, 2(1), 42-43.

Clark, R. M. (2007, 8th May 2007). The birth and development of scientific intelligence. Scientific and technical intelligence analysis Retrieved 4th October 2005, from https://www.cia.gov/library/center-for-the-studyof-intelligence/kent-csi/docs/v19i1a06p 0001.htm

Copeland, B. J. (1998). Turing's O-machines, Searle, Penrose and the brain. Analysis, 58, 128-138.

Copeland, B. J., \& Proudfoot, D. (1999). Alan Turing's Forgotten Ideas in Computer Science. Scientific American, 280(4), 98-103.

Croarken, M. (1993). The Beginnings of the Manchester Computer Phenomenon: People and Influences. IEEE Annals of the History of Computing, 15(3), 9-16.

Davis, M. (1982). Computability and Unsolvability (3rd ed.). New York: Dover.

Davis, M. (2004). The myth of hypercomputation. In C. Teuscher (Ed.), Alan Turing: Life and legacy of a great thinker (pp. 195-212). Heidelberg: Springer.

Davis, M. (2006). Why there is no such discipline as hypercomputation. Applied Mathematics and Computation, $178(1), 47$.

Evans, C. R. (1975). Interview with Maxwell Herman Alexander Newman. Unpublished Interview (Transcript by David P. Anderson). Science Museum / National Physical Laboratory.

Evans, C. R. (1976a). Interview with Allen William Mark 'Doc' Coombs. Unpublished Interview (Transcript by David P. Anderson). Science Museum / National Physical Laboratory.

Evans, C. R. (1976b). Interview with Andrew Donald Booth. Unpublished Interview (Transcript by David P. Anderson). Science Museum / National Physical Laboratory.

Evans, C. R. (1976c). Interview with Donald Michie. Unpublished Interview (Transcript by David P. Anderson). Science Museum / National Physical Laboratory. 
Evans, C. R. (1976d). Interview with Donald Watts Davies. Unpublished Interview (Transcript by David P.

Anderson). Science Museum / National Physical Laboratory.

Evans, C. R. (1976e). Interview with Frederic Calland Williams. Unpublished Interview (Transcript by David P.

Anderson). Science Museum / National Physical Laboratory.

Evans, C. R. (1976f). Interview with Harold Douglas Huskey. Unpublished Interview (Transcript by David P.

Anderson). Science Museum / National Physical Laboratory.

Evans, C. R. (1976g). Interview with Herman Heine Goldstine. Unpublished Interview (Transcript by David P.

Anderson). Science Museum / National Physical Laboratory.

Evans, C. R. (1976h). Interview with Isidore Jacob (Jack) Good. Unpublished Interview (Transcript by David P.

Anderson). Science Museum / National Physical Laboratory.

Evans, C. R. (1976i). Interview with James Hardy Wilkinson. Unpublished Interview (Transcript by David P.

Anderson). Science Museum / National Physical Laboratory.

Evans, C. R. (1976j). Interview with Thomas Harold Flowers. Unpublished Interview (Transcript by David P.

Anderson). Science Museum / National Physical Laboratory.

Evans, C. R. (1976k). Interview with Tom Kilburn. Unpublished Interview (Transcript by David P. Anderson).

Science Museum / National Physical Laboratory.

Frankel, S. (1972). Private communication with Prof. Brian Randell.

Good, I. J. (1945-8). Early Notes on Electronic Computers. (with an introduction dated 23rd March 1972).

Good, I. J. (1950). Probability and the weighing of evidence. London: C. Griffin.

Hilbert, D., \& Ackerman, W. (1928). Grundzüge der theoretischen Logik. Berlin: Springer-Verlag.

Hodges, A. (1992). Alan Turing: The Enigma.: Vintage.

Hodges, A. (1999). The Professors and the Brainstorms. Retrieved 5th November 2004, from

http://www.turing.org.uk/philosophy/sciam.html

Hodges, A. (2004). Alan Mathison Turing (1912-1954). Oxford Dictionary of National Biography Retrieved 5th

November 2004, from http://www.oxforddnb.com/view/article/36578

Hodges, A. (2007). Alan Turing: The logical and physical basis of computing. from

http://www.bcs.org/server.php?show=nav.00100v005003001003

Jones, R. V. (1978). Private communication with Andrew Hodges: 7th February 1978. Unpublished Letter.

Kahn, D. (1976). Transcript of interview with Professor I.J. Good.

Kilburn, T. (1947). A Storage System for Use with Binary Digital Computing Machines: Telecommunications Research Establishment.

Lavington, S. H. (1976). Interview with Mike Woodger. Unpublished Interview (Transcript by David P. Anderson).

Science Museum / National Physical Laboratory.

Lavington, S. H. (1998). A History of Manchester Computers (2nd ed.): British Computer Society.

Lavington, S. H. (2005). Personal communication with David Anderson. Unpublished e-mail.

Lindeberg, J. W. (1922). Eine neue Herleitung des Exponentialgesetzes in der Wahrscheinlichkeitsrechnung

Mathematische Zeitschrift, 15(1), 211-225.

Mahoney, M. S. (1988). The history of computing in the history of technology. IEEE Annals of the History of Computing, 10(2), 113-125. 
Mahoney, M. S. (2002). Software as Science - Science as Software. In U. Hashagen, R. Keil-Slawik \& A. Norberg (Eds.), History of Computing: Software Issues. Berlin: Springer-Verlag.

Matiyasevich, Y. (1970). Enumerable sets are Diophantine. Doklady Mathematics (Doklady Akademii Nauk). , 11(2), 279-282.

Michie, D. (2001). Personal Communication with David Anderson, 12th February 2001. Unpublished e-mail.

Napper, R. B. E. (1998). Newman's Contribution to the Mark 1 Machines. Retrieved 6th December 2005, from http://www.computer50.org/mark1/newman.html

Napper, R. B. E. (2004, 1st June). Comment on "The Moore School Lectures and the British Lead in Stored Program Computer Development (1946 - 1953)". Retrieved 11th December 2005, from http://www.virtualtravelog.net/entries/2003/10/the moore school lectures and the british lead in stored program computer development 1946 1953.html

Neumann, J. v. (1945). First Draft of a Report on the EDVAC. In N. Stern (Ed.), From ENIAC to UNIVAC: An Appraisal of the Eckert-Mauchly Computers (pp. 296): Digital Press (1981).

Newman, L. (1945). Letter to Hella Weyl. Unpublished Letter.

Newman, L. (1948). Letter to Antoinette, Viscountess Esher. Unpublished Letter.

Newman, M. H. A. (1945). Letter to Colonel Wallace, D.D.(A), Government Communications Headquarters, Bletchley Park, 8th August 1945 Unpublished letter.

Newman, M. H. A. (1946a). Letter to John von Neumann, 8th February 1946. Unpublished Letter.

Newman, M. H. A. (1946b). Project for a Calculating Machine Laboratory in Manchester University. Unpublished Letter to the Secretary of the Royal Society.

Newman, M. H. A. (1949). Progress of Computing Machine Project. Unpublished Report included as Appendix A: Minutes of the Council of the Royal Society, 13th January 1949.

Newman, W. (2002). Married to a mathematician: Lyn Newman's life in letters. The Eagle, St. John's College Cambridge, 47-55.

Randell, B. (1972). On Alan Turing and the Origins of Digital Computers. Machine Intelligence, 7, 3-22.

Randell, B. (1975). Interview with Professor M.H.A. Newman 1st November 1975. Unpublished Interview transcript.

Report of Interdepartmental Technical Committee on a Proposed Central Mathematical Station. (1944).): Department for Scientific \& Industrial Research.

Royal Society. (1946a). Meeting of the Government Grant Board B, 11th April 1946. Unpublished Minutes. Royal Society. (1946b). Meeting of the Government Grant Board B, 11th July 1946. Unpublished Minutes. Royal Society. (1946c). Meeting of the Government Grant Board B, 16th May 1946. Unpublished Minutes.

The National Archives. (1943). Photographs of Colossus. Catalogue reference: FO 850/234) with captions by Benjamin.

Turing, A. M. (1936). On computable numbers, with an application to the Entscheidungsproblem. Proceedings of the London Mathematical Society, Series 2(42), 230-265.

Turing, A. M. (1946). Proposed electronic calculator. Unpublished report for the National Physical Laboratory.

Turing, E. S. (1959). Alan M. Turing: Mathematician and Scientist. Cambridge: Heffer.

Ulam, S. (1999). Letter to Andrew Hodges, 16th April 1979. Unpublished letter.

Whitehead, J. H. C. (1946). Letter to M.H.A. Newman, 27th January 1946. Unpublished Letter. 
Wilkes, M. (1985). Memoirs of a computer pioneer: Massachusetts Institute of Technology Cambridge, MA, USA. Williams, F. C. (1972). Private Communication with B. Randell. Unpublished Letter.

Williams, F. C. (1975). Early computers at Manchester University. The Radio and Electronic Engineer 45(7). 